IZA DP No. 10101

Long-term Consequences of Workplace Bullying on Sickness Absence

Tine L. Mundbjerg Eriksen

Annie Hogh

Åse Marie Hansen

July 2016 


\title{
Long-term Consequences of Workplace Bullying on Sickness Absence
}

\author{
Tine L. Mundbjerg Eriksen \\ Aarhus University \\ and IZA
}

Annie Hogh

Copenhagen University

Åse Marie Hansen

Copenhagen University

and NRCWE, Copenhagen

Discussion Paper No. 10101
July 2016

IZA

P.O. Box 7240

53072 Bonn

Germany

Phone: +49-228-3894-0

Fax: +49-228-3894-180

E-mail: iza@iza.org

Any opinions expressed here are those of the author(s) and not those of IZA. Research published in this series may include views on policy, but the institute itself takes no institutional policy positions. The IZA research network is committed to the IZA Guiding Principles of Research Integrity.

The Institute for the Study of Labor (IZA) in Bonn is a local and virtual international research center and a place of communication between science, politics and business. IZA is an independent nonprofit organization supported by Deutsche Post Foundation. The center is associated with the University of Bonn and offers a stimulating research environment through its international network, workshops and conferences, data service, project support, research visits and doctoral program. IZA engages in (i) original and internationally competitive research in all fields of labor economics, (ii) development of policy concepts, and (iii) dissemination of research results and concepts to the interested public.

IZA Discussion Papers often represent preliminary work and are circulated to encourage discussion. Citation of such a paper should account for its provisional character. A revised version may be available directly from the author. 


\title{
ABSTRACT
}

\section{Long-term Consequences of Workplace Bullying on Sickness Absence ${ }^{*}$}

\begin{abstract}
Bullying in workplaces is a problem thought to harm individual productivity. This paper investigates whether being exposed to bullying in the workplace increases long-term sickness absence. We analyze employees from a selection of workplaces from The Bullying Cohort Study conducted in Denmark in 2006. The Negative Acts Questionnaire-Revised was used to avoid bias related to self-labeling as being bullied. We account for important confounders, such as historical information on sickness absence and mental health, obtained through rich registry data. Our results show that gender does not significantly explain exposure to bullying and that exposure to bullying is associated with negative immediate selfreported health for both genders. We also find, however, that only bullied females have higher, persistent increases in long-term sickness absence and adverse long-term health. This suggests that men and women have different coping strategies. We investigate plausible explanations for this and find that the differences cannot be explained by, for example, turnover or lack of employment. Although insignificant, our results nonetheless indicate that men are twice as likely to leave the labor force immediately after exposure to bullying.
\end{abstract}

JEL Classification: $\quad \mathrm{J} 15, \mathrm{~J} 24, \mathrm{~J} 81$

Keywords: $\quad$ working environment, harassment, absenteeism, health, gender

Corresponding author:

Tine L. Mundbjerg Eriksen

Department of Economics and Business

Aarhus University

Fuglesangs Allé 4

DK-8210 Aarhus $\mathrm{V}$

Denmark

E-mail: teriksen@econ.au.dk

\footnotetext{
* We thank the Danish Psychiatric Central Register for access to data. We further thank the Danish Working Environment Research Foundation (file no. 20050072524/4) and the National Research Centre for the Working Environment (NRCWE), Denmark for supporting the study. The data used stem from an NRCWE study called Collaboration and Working Climate: Prevention of Bullying at Work (Samarbejde og Arbejdsklima - Forebyggelse af Mobning på Arbejdspladsen). Tine Louise Mundbjerg Eriksen conducted all the analyses and is therefore responsible for the conclusions. We would like to thank the editor, Emilia Simeonova, two anonymous referees, Knut Røed, Helena Skyt Nielsen, Marianne Simonsen, participants at the $9^{\text {th }}$ International Conference on Workplace Bullying and Harassment and seminar participants at Aarhus University for valuable comments.
} 


\section{Introduction}

Public expenditures related to sickness absence are staggering. In 2008 the Organisation for Economic Co-operation and Development (OECD) countries spent an average of $1.2 \%$ of their gross domestic product on disability and $0.8 \%$ on sickness benefits (OECD, 2010). According to OECD (2010), 50-90\% of the individuals receiving disability benefits did so after a period of sickness absence. Sickness absence can therefore be considered very costly to society. ${ }^{1}$ While various economic research, e.g. Ziebarth and Karlsson (2010, 2014) and Johansson and Palme (2005), has mainly focused on how economic incentives affect the duration of sickness absence, only few researchers investigate how factors pertaining to the work environment affect sickness absence. Ose (2005) finds that a poor work environment increases long-term sickness absence, while Røed and Fevang (2007) find that the process of downsizing increases the level of sickness absence among nurses still working.

One relevant factor related to the work environment is bullying. Previous research shows that bullying can have severe detrimental consequences for the individual's health and well-being, which is likely to induce reduced productivity in firms and society (Vartia, 2001, Kivimäki et al., 2003, Niedhammer et al., 2006). At the same time, prevalence rates are high, ranging from an average of $4-10 \%$ of workers in Scandinavian countries to 14$25 \%$ of workers in other non-Scandinavian countries (Nielsen et al., 2010). ${ }^{2}$ Despite this, studies documenting the effect of bullying on economic outcomes are scarce. Kivimaki et al. (2000) find a positive relationship between bullying and sickness absence in hospital staff, while Ortega et al. (2011) find the same in a sample of employees in the elderly care sector. These studies, however, only correct for previous health and sickness absence to a minor extent, and they only consider spells of absence within the first year after bullying is observed. If exposure to bullying leads to severe health issues, such as depression, it is likely that individuals will also suffer in the long run. This paper investigates the long-term consequences of workplace bullying for men and women while, in contrast to previous literature, adjusting for important confounders such as previous employee health and sickness absence history.

\footnotetext{
${ }^{1}$ Additional costs that should be considered include, e.g., healthcare costs and foregone productivity.

${ }^{2}$ Prevalence rates depend on the measure of bullying being used.
} 
We contribute to the existing literature in several ways. First, as mentioned above, little knowledge is available on the impact of workplace bullying on sickness absence, especially the long-term consequences remain to be investigated. Second, the empirical analyses are based on a unique dataset combining information on bullying, psychosocial work environment, negative acts, and other related work environmental measures from The Bullying Cohort Study with rich Danish registry data such that issues concerning common variance bias and reverse causality are limited. ${ }^{3}$ Third, our analysis employs the well-documented Negative Acts Questionnaire-Revised (NAQ-R) to measure bullying (Einarsen et al., 2009). Instead of employing a self-assessment of whether the individual feels bullied, the NAQ-R asks about exposure to specific actions, making it a more objective measure of bullying comparable across individuals. The NAQ-R consists of 21 items on various negative actions. We follow the literature (e.g. Mikkelsen and Einarsen, 2001 and Nielsen et al., 2009) and define individuals as a target of bullying if they have been subject to a minimum of two negative actions weekly within the past six months. Fourth, while we acknowledge that identification is particularly difficult due to non-random selection of targets, our study controls for a rich set of variables descriptive of both exposure to bullying and worker health. The conditioning set includes previous sickness absence, prescription drug usage, mental and behavioral diagnoses, socio-economic status, workplace fixed effects, and demographics. ${ }^{4}$ As possible confounders may still be a concern, we test the robustness of our results to the inclusion of personality traits and work environment characteristics. Finally, we investigate whether health, turnover, presenteeism (attending work while sick), and health are channels through which bullying may affect sickness absence.

Seven percent of the respondents in our sample can be identified as having been exposed to bullying in 2006. Our results show that, while gender does not explain exposure to bullying once we condition on workplace fixed effects, a significant and negative relationship only exists between workplace bullying and sickness absence for women. For females, being exposed to workplace bullying is associated with more than double the amount of long-term sickness absence compared to their non-bullied female

\footnotetext{
${ }^{3}$ The Bullying Cohort Study was conducted by the National Research Centre for the Working Environment (NRCWE) in Denmark in 2006.

${ }^{4}$ All control variables are measured in 2005 or earlier.
} 
coworkers. This suggests that reducing bullying by $50 \%$ corresponds to an effect of increasing the cost of sickness absence by $5 \%$ if Johansson and Palme's (2005) cost elasticity for long-term spells of absence for women is applied. The relationship persists for two years before fading away. The results are robust to the inclusion of personality and work environment characteristics.

A further investigation of the health of the individuals shows that, although men and women are bullied to the same extent and being exposed to bullying is associated with adverse immediate self-reported health for both genders, bullying is only related to adverse long-term health for women. This suggests that men and women have different coping strategies. We investigate a number of plausible explanations and find that when exposed to workplace bullying, neither men nor women have more short-term $(<2$ weeks) sickness spells of absence than their non-bullied coworkers. Differences do not appear to be due to either turnover or lack of employment either, although women appear to be significantly more likely to have left the workplace after four years, which could explain the reduction in long-term sickness absence after 2009 for this subgroup. Our findings, show, however, that men report higher levels of presenteeism and are four percentage points more likely to leave the labor force immediately after exposure to bullying (the coefficients are insignificant, possibly due to the small sample size). These may explain why men do not have more long-term sickness absence when exposed to bullying.

The remainder of this paper is structured as follows: The next section discusses why workplace bullying is likely to have negative consequences for the individual. Section 3 then presents the available data, explains how we identify bullying and describes our outcomes and the conditioning set. Next, section 4 presents the results and section 5 carries out a range of robustness checks, while section 6 discusses possible mechanisms. Finally, section 7 concludes.

\section{Why Does Bullying Affect Sickness Absence?}

Bullying can be defined as a situation where a person is repeatedly, over a longer period of time, subject to negative actions from which he or she finds it difficult to defend him- or herself. 
(e.g., Hansen et al. (2011)).

Negative actions are defined as behaviors which, when they occur on a regular basis, can cause severe harm to the individual (Einarsen et al., 2009). Examples include social exclusion, being yelled at, and physical violence. According to this definition, in order for the actions to qualify as bullying, they have to persist over a longer period of time ${ }^{5}$ and the power relationship between the target and the perpetrator(s) must be asymmetrical, such that the target is unable to defend him or herself. As mentioned above, however, little is known about the long-term consequences of these negative actions.

According to psychological stress theory, stress occurs when an imbalance exists between the demands or challenges individuals face and their own resources (Bakker and Demerouti, 2007). At the workplace these stressors, as they are often called, typically consist of e.g., workload, role uncertainty, time pressure, and conflicts. Most people will experience stressful events during the course of their life but if the events persist over a longer period, it may be harmful to the individual's health. As the definition above highlights, bullying must persist for a longer period to result in the likely adverse health effects. Similarly strain theory (Agnew, 1992) also suggests that bullying has negative consequences for the individual's health. Individuals who experience a strain (such as bullying) may produce negative emotions such as anger, frustration, anxiety, or depression, which may lead to a corrective action in terms of, for instance, wrongdoing, self-harm or suicide. Thus, from a theoretical perspective, bullying is likely to affect the individual's health, which may in turn affect sickness absence.

Economists have mainly focussed on how economic incentives affect sickness absence. In their analysis, Johansson and Palme (2005) utilize changes in the replacement rates of sickness benefits in Sweden. Using a differences-in-differences model and Cox proportional hazard regressions, they find that the duration of sickness absence is negatively related to cost increases but positively related to cost decreases. Using the results from the Cox regressions, they find a cost elasticity of -0.87 for durations between eight and 90 days for women. Ziebarth and Karlsson (2010) exploit a reduction in the replacement rate from 100 to $80 \%$ for private employees in Germany in 1996. Comparing the affected private employees with a matched sample of non-affected public employees, they find

\footnotetext{
${ }^{5}$ The norm within the existing literature is six months.
} 
that the reduction of $20 \%$ in the replacement rate increases the share of non-absent employees by $6.5 \%$. At the same time, the reduction cuts the number of days of absence in the $50-70^{\text {th }}$ percentile by approximately $12 \%$. Some unions were able to negotiate retainment of a $100 \%$ replacement rate, which meant that a selection of private employees were not affected by the cut in the replacement rate. When Ziebarth and Karlsson (2010) compare the non-affected private employees with affected private employees, they find that the reduction in the replacement rate increases absence by $28 \%$. Ziebarth and Karlsson (2014) exploit that the same reform was rolled back in 1999 such that replacement rates returned to $100 \%$. Using the same approach, as in their previous paper, they find that increasing the replacement rate by $25 \%$ increased the number of sick days for the treated individuals by $10 \%$. The resulting arc elasticity resembles the cost elasticities in Johansson and Palme (2005).

While we have been unable to find economic papers that study the effect of working conditions on health, a few studies do investigate how working conditions affect absenteeism. Røed and Fevang (2007) study how downsizing, which can be thought to affect, e.g., job security, workload, and role uncertainty, leads to increased sickness absence among nurses in Norway. Using a competing risks hazard model, they find that downsizing exceeding $20 \%$ increases the hazard into sickness absence by $7 \%$ and decreases the hazard out of sickness by $10 \%$ of nurses still employed.

Bratberg and Monstad (2015) utilize a financial shock in Norway in 2007 that only hit some local authorities. Using a differences-in-differences approach, they compare public employees hit by the shock to public employees not hit by the shock. Their findings indicate that an increase in job insecurity has a disciplinary effect in that experiencing the shock decreased the level of sickness absence by $10 \%$ for women and $23 \%$ for men. This is in line with results by Ichino and Riphahn (2005), who find, that at the end of the initial probationary period when full job protection is granted, absenteeism increased among white-collar workers in an Italian bank.

Ose (2005) incorporates working conditions in an efficiency wage model to explain voluntary and involuntary absences. She tests the model on Norwegian data. In Norway, long-term sickness absence require a doctor's note, whereas short-term ( $<3$ days) spells of sickness absence do not. As a result, short-term absence is considered voluntary 
absence, while long-term absence is considered involuntary absence due to actual illness. Ose's results support the theoretical model in that wages only affect short-term absence. The working environment factors influence both short-term and long-term absence, indicating that workers are not fully compensated. Johansson and Palme (1996) find that accidents at work and work-related diseases increase work absence.

To our knowledge no economic studies exist examining the effect of bullying on health or sickness absence. Studies within the field of organizational psychology, however, show that bullying is associated with increased levels of sickness absence. In a study of hospital staff in Finland, Kivimaki et al. (2000) find that being subject to bullying is associated with an increase in medically certified sickness absence. ${ }^{6}$ In a sample of elderly care workers (96.3\% were women), Ortega et al. (2011) find that frequent bullying is associated with increased levels of long-term ( $>6$ consecutive weeks) sickness absence within the year after bullying was observed. ${ }^{78}$ Other studies find that being exposed to bullying as well as witnessing bullying is associated with depressive symptoms, general stress and mental stress reactions, psychosomatic and psychological stress symptoms (Niedhammer et al., 2006, Agervold and Mikkelsen, 2004, Hansen et al., 2011, Vartia, 2001). In general, targets of bullying report lower well-being, lower self-esteem, sleep problems, anxiety, concentration difficulties, fatigue, burnout, anger, depression, and stress symptoms (see, e.g., Nielsen and Einarsen, 2012). The previous literature thus suggests that bullying leads to increased absenteeism and adverse health, although causal relationships have not been established.

While this section discussed how bullying may affect sickness absence and highlighted health as a possible mechanism through which bullying affects health, other plausible channels are conceivable. Individuals may choose to leave the workplace or the workforce, or attend work although they feel sick, in which case we would expect to see little or no effect on sickness absence. Section 6 investigates whether bullying affects short-term or long-term health, whether it affects short-term sickness absence, whether it leads to

\footnotetext{
${ }^{6}$ The results were adjusted for demographic characteristics, occupational background, behavioral risks, chronic diseases, and baseline sickness absence.

${ }^{7}$ They control for age, gender, occupational groups, body mass index, smoking habits, children, cohabitation, and psychosocial work environment factors. They do not account for previous health.

${ }^{8}$ The two previous studies all measure bullying based on self-labeling. To our knowledge, no other study considers the relationship between bullying measured by negative actions and sickness absence.
} 
increases in turnover or changes in employment and labor force participation. Finally 6 also studies whether bullying affects presenteeism.

\section{Data}

This section summarizes the data used in the empirical analysis. We start by introducing the sample. Second, we describe how we identify targets of bullying. We then explain the outcomes that we employ in the main analysis. The final subsection describes our conditioning set and conducts a probit regression of the propensity to be bullied.

The data stem from the Bullying Cohort Study conducted in 2006 by the Danish National Research Centre for the Working Environment (NRCWE) ${ }^{9}$ which recruited workplaces via an online open invitation on the websites of professional organizations. Ninety companies (28 private and 62 public) showed interest in the study, but only companies with more than 30 employees were asked to attend, leaving 79 eligible companies of which 60 (22 private, 38 public) agreed to participate. ${ }^{10}$ The companies provided NRCWE with employee email addresses, after which questionnaires were sent directly to employees with a return envelope to NRCWE. There were 3358 people who responded to the questionnaire, giving a response rate of $45.9 \%{ }^{11}$

The questionnaire does not focus solely on bullying but instead contains a long list of questions of a demographic nature and items on the psychosocial work environment, negative acts, bullying, physical and psychological stress reactions, health, sleep, and sickness absenteeism. The survey data are merged with the Danish registry data using the respondents' civil registration number. The registry data contain information on a large number of important characteristics such as demographics, socio-economic status, current employment, workplace identifiers, prescription drug use, and somatic and psychiatric diagnoses from general hospitals. In addition, the data are augmented with data from the Danish Register for Evaluation of Marginalization (DREAM) collected by the Danish Ministry of Employment. DREAM contains weekly information on everyone in Denmark who collects government benefits, thus enabling us to obtain precise infor-

\footnotetext{
${ }^{9}$ The questionnaires were collected from September 2006 to November 2006.

${ }^{10} \mathrm{~A}$ few daycare centers were allowed to participate even though they had less than 30 employees.

${ }^{11} \mathrm{~A}$ contains information on attrition.
} 
mation on sickness absenteeism as well as information on, for example, unemployment, previous labor market history, and previous sickness absence history.

We restrict the sample to the 54 companies that had more than ten employees respond to the questionnaire to make sure that we match workers and workplaces correctly. ${ }^{12}$ We are able to identify the corresponding workplaces in the registries, resulting in 136 workplaces. A workplace is defined as a physical place. A company can, however, have multiple branches placed throughout the country, in which case we may be comparing individuals who, for instance, are not generally in contact with one another, answer to the same manager, or have the same colleagues, if we conduct the fixed effect analysis based on companies. We further delete workplaces where less than three employees respond to the items on bullying as we use fixed effects in the empirical analysis. This gives us a sample of 54 companies divided into 104 workplaces with 3227 respondents. We delete another 27 respondents because the data indicate that they are retired before the survey period. Finally, we delete 18 respondents as they did not respond to the NAQ-R, thus reducing the final number of respondents to 3182 employees in 104 workplaces. ${ }^{13}$ An obvious concern is whether the companies who attended the study did so because they faced problems related to bullying and sickness absence. Unfortunately, we cannot determine the level of bullying in firms that did not participate in the survey. Data on levels of long-term sickness absence for all working individuals in Denmark are, however obtainable. Comparing means, we find that, although the differences in long-term sickness absence are significant, there seems to be no systematic pattern between the firms who participate in the survey and the general population of firms within industries (see B).

\subsection{Identifying bullying}

We identify exposure to workplace bullying using the 21-item NAQ-R (Einarsen et al., 2009), a scale widely used in workplace bullying literature whose external validity has

\footnotetext{
${ }^{12}$ The employees were surveyed from September 2006 to November 2006 and information on place of employment in the Danish registry data is based on employment in November 2006.

${ }^{13}$ The main results are unchanged using the full sample of respondents (3312 observations) who are not retired prior to the survey period.
} 
been confirmed by a number of studies. ${ }^{14}$ The questionnaire measures various negative actions (NA) such as "Someone withholding information which affects your performance", "Being humiliated or ridiculed in connection with your work," and "Being ignored or excluded". The respondents are asked how often they have been exposed to the NA ("Never"; "Now and then"; "Monthly"; "Weekly"; or "Daily") within the past six months. C shows the full questionnaire. The scale shows good internal validity with a Kaiser-Meyer-Olkin measure of sampling adequacy (KMO) of 0.93 and a Cronbach's Alpha of 0.88 (see F). Note in particular that the NAQ-R was asked before any mentioning of the word bullying in the questionnaire.

Following the literature (e.g. Mikkelsen and Einarsen, 2001 and Nielsen et al., 2009), we identify a respondent as being a target of bullying if individuals reply that they have been subject to at least two NA daily or weekly during the past six months. ${ }^{15}$ Based on this definition $7 \%$ of the respondents are exposed to workplace bullying, which is similar to previously reported prevalence rates using two NA as the cut-off criteria (Nielsen et al., 2009 and Mikkelsen and Einarsen, 2001). Forty-nine percent of the bullied individuals report more than two NA, and the average number of actions reported is approximately three. More than $30 \%$ of the bullied individuals report that they experience that "someone withholds information that affects their performance", "they are given unreasonable deadlines", and "are ordered to work below their level of competence" weekly or daily. About $13 \%$ report that they are "being excluded", "humiliated" or "subject to gossip" at least weekly, $9 \%$ even say that they are "being shouted at or subject to spontaneous anger" weekly or daily. We observe more NA related to the respondent's work, but still a fair amount of individuals are subject to actions related to their person. The full list of frequencies are reported in the table in C. ${ }^{16}$

A common concern when measuring bullying is measurement error. Although the

\footnotetext{
${ }^{14}$ Nielsen et al. (2010) find 16 studies based on the NAQ-R in a meta-analysis of measurement methods for workplace bullying.

${ }^{15}$ The conclusions are robust to alternative definitions of bullying. In general we find that just experiencing one NA compared to zero NA does not increase long-term absence. Experiencing two or more NA significantly increases sickness absence. Using a continuous measure of the number of NA, the coefficient is positive and significant (at a 10\% level in 2007 and at a $5 \%$ level in 2008 and 2009). We also find indications that the more NA an individual is exposed to, the larger the coefficient on bullying. Results available from the authors upon request.

${ }^{16}$ The results do not appear to be driven by any particular negative action. Results available from the authors upon request.
} 
individuals are asked to rate exposure to a set of specific actions instead of self-labeling themselves as being bullied, whether someone, for example feels that they are "being excluded" is still a subjective evaluation. Thus, what may make one person feel excluded may not be the case for someone else. The questionnaire also presents the respondents with a definition of bullying and asks whether any of their colleagues have been exposed to bullying within the past six months. We use this to study the connection between being identified as bullied and having coworkers report that a colleague is subject to bullying. Only two out of 104 workplaces have an individual identified as a target of bullying without colleagues reporting that they witness bullying. In 72 workplaces, someone is a target of bullying and coworkers also reporting that they witness bullying. In 16 workplaces a colleague reports witnessing bullying but no one is identified as a target of bullying. These figures indicate that there may be a tendency to underreport NA as there are plausible negative connotations associated with them. Another possible explanation is that the non-respondents in a workplace are more likely to be exposed to bullying. Insofar that bullying leads to poorer health and more sickness absence, this selection will tend to bias our results downwards.

\subsection{Outcomes}

Our main outcome is the average amount of long-term sickness absence annually from 2007 to 2011. In Denmark, people are entitled to compensation due to sickness absence for 52 out of the past 78 weeks regardless of whether they receive unemployment benefits, are in subsidized employment, or are in regular employment. ${ }^{17}$ If someone is employed, the right to wages during sick leave depends on the contract. However, the employer is, in any case, obliged to pay the equivalent of sickness benefits during the first three weeks of absence. Afterwards, the local authority covers payments equal to the amount of sickness benefits (about USD700/week in 2013). DREAM only registers the benefits covered by the local authority, which means that we only observe spells of sickness absence with durations of more than three weeks for individuals employed in the private sector. For this reason, we only consider spells of absence that last more than three weeks. From 2001 to 2011, we add together the individual's weeks of sickness absence

\footnotetext{
${ }^{17}$ In special cases, it can be extended by up to a year.
} 
annually in excess of three weeks if the spells are at least three weeks long.

Table 1: Weeks of Long-Term Sickness Absence by Bullying Status

\begin{tabular}{|c|c|c|c|c|c|c|}
\hline & \multicolumn{3}{|c|}{ Bullied } & \multicolumn{2}{|c|}{ Non-Bullied } & \multirow[b]{2}{*}{ No. Obs. } \\
\hline & Mea & & Std. Dev. & Mean & Std. Dev. & \\
\hline Sickness Absence 2001 & 0.421 & & 2.480 & 0.393 & 3.047 & 3182 \\
\hline Sickness Absence 2002 & 0.522 & & 3.491 & 0.464 & 2.945 & 3182 \\
\hline Sickness Absence 2003 & 0.531 & & 3.626 & 0.644 & 3.921 & 3182 \\
\hline Sickness Absence 2004 & 0.583 & & 3.699 & 0.587 & 3.668 & 3182 \\
\hline Sickness Absence 2005 & 0.553 & & 3.119 & 0.660 & 3.839 & 3182 \\
\hline Sickness Absence 2006 & 1.281 & $* *$ & 5.331 & 0.711 & 3.794 & 3182 \\
\hline Sickness Absence 2007 & 2.465 & $* * *$ & 8.488 & 1.149 & 5.615 & 3182 \\
\hline Sickness Absence 2008 & 2.474 & $* * *$ & 8.580 & 1.015 & 5.282 & 3182 \\
\hline Sickness Absence 2009 & 2.311 & $* * *$ & 8.422 & 1.045 & 5.484 & 3182 \\
\hline Sickness Absence 2010 & 1.978 & $* *$ & 8.568 & 1.082 & 5.383 & 3182 \\
\hline Sickness Absence 2011 & 1.658 & $*$ & 7.003 & 1.015 & 4.951 & 3182 \\
\hline
\end{tabular}

Table 1 presents the means and standard deviations of yearly long-term sickness absence. From 2001 to 2005, we observe no significant differences between targets and their non-bullied co-workers. In 2006, the year of the survey, individuals exposed to bullying have significantly more sickness absence. This is to be expected as respondents are asked whether they have been subject to NA within the past six months prior to the time of the survey, which was conducted in the latter half of 2006. Thus, if bullying increases sickness absence, we should already observe a difference in 2006 . We will return to this issue in section 4.1. We continue to observe significant differences in weeks of long-term sickness absence between bullied employees and their non-bullied coworkers from 2007 to 2010. The average amount of sickness absence ranges from two to three weeks. In section 4 , we investigate whether these differences persist when controlling for possible confounders and workplace fixed effects.

\subsubsection{A note on employment}

Although sickness absence is also registered for the individuals who receive unemployment benefits or are in subsidized employment, the incentives for these people to register sickness absence may be less pronounced. A relevant argument is therefore that the lack of difference in sickness absence before 2006 and the decrease in the difference in absence after 2009 in Table 1 is due to the fact that the individuals who were exposed to bullying 
are now unemploymed, or even worse, outside the labor force. Table 2 shows employment rates from 2001 to 2011. ${ }^{18}$ Only in 2001 and 2002 do we observe a significant difference in employment rates between the bullied and non-bullied. ${ }^{19}$ The employment rates increase up until 2006, which is to be expected since being employed in 2006 is a stipulation for participating in the survey. The rates then drop again subsequently. The trend seems to be the same for bullied and non-bullied individuals, suggesting that employment is not a particular concern. In section 6 , however, we will investigate a measure of being out of the labor force in order to address the decrease in sickness absence in 2010 and 2011.

Table 2: Employment Rates by Bullying Status

\begin{tabular}{llllccc}
\hline & \multicolumn{3}{c}{ Bullied } & \multicolumn{2}{c}{ Non-Bullied } \\
& \multicolumn{2}{c}{ Mean } & Std. Dev. & Mean & Std. Dev. & No. Obs. \\
\hline Employment Rates 2001 & 0.798 & $* * *$ & 0.402 & 0.865 & 0.342 & 3182 \\
Employment Rates 2002 & 0.807 & $* *$ & 0.396 & 0.872 & 0.334 & 3182 \\
Employment Rates 2003 & 0.851 & 0.357 & 0.883 & 0.322 & 3182 \\
Employment Rates 2004 & 0.873 & 0.334 & 0.905 & 0.293 & 3182 \\
Employment Rates 2005 & 0.930 & 0.256 & 0.940 & 0.237 & 3182 \\
Employment Rates 2006 & 0.987 & 0.114 & 0.976 & 0.153 & 3182 \\
Employment Rates 2007 & 0.908 & 0.290 & 0.936 & 0.245 & 3182 \\
Employment Rates 2008 & 0.868 & 0.339 & 0.897 & 0.304 & 3182 \\
Employment Rates 2009 & 0.855 & 0.353 & 0.880 & 0.325 & 3182 \\
Employment Rates 2010 & 0.846 & 0.361 & 0.849 & 0.358 & 3182 \\
Employment Rates 2011 & 0.825 & 0.381 & 0.823 & 0.382 & 3182 \\
\hline Notes: Means are tested against the mean of the Non-Bullied. (***): Significant at a \\
1\% level. (**): Significant at a 5\% level. (*): Significant at a 10\% level.
\end{tabular}

\subsection{The conditioning set}

The relationship between bullying and sickness absence is likely to be confounded by a large range of different characteristics. In this section we describe the characteristics previously identified as important antecedents and traits of targets of bullying. This is followed by a description of the conditioning set employed in the analysis below.

Researchers in psychology and sociology have long tried to identify traits that increase

\footnotetext{
${ }^{18}$ Employment is defined as having at least six months of accumulated work experience within the given year.

${ }^{19}$ If we define employment as having at least nine months accumulated work experience, employment levels show the same pattern and are only significantly different for bullied and non-bullied individuals in 2001 at a $10 \%$ significance level. Results are available from the authors upon request.
} 
the risk of exposure to bullying. According to the definition of bullying some asymmetry in the power relationship between the parties has to persist in order for episodes to classify as bullying. This suggests that characteristics such as seniority, age, level of education, and ethnicity are likely antecedents of bullying. However, previous findings are inconclusive as to whether demographic characteristics, like being older and having a higher education, reduce the probability of being bullied (See, e.g., Mikkelsen and Einarsen, 2001, Hogh et al., 2005).

Work related characteristics such as demands, management style, job security, and organizational changes have been associated with workplace bullying. Although gender does not seem to affect whether the individual is exposed to bullying (e.g., Hogh et al., 2005), bullying does seem to thrive in workplaces dominated by one gender (Matthiesen and Einarsen, 2007 and Eriksen and Einarsen, 2004). Minorities are more frequently subject to bullying as they create an implicit difference in power (see the definition of bullying). Belonging to the dominated gender is similar to belonging to a minority. At the same time, the perception of the pattern of gender roles may further induce bullying of the minority (e.g., male nurses, female carpenters). Similarly, employees with lower hierarchical status in the workplace are more frequently exposed to bullying (Aquino, 2000).

Aquino and Bradfield (2000) investigate whether certain personality traits are more likely to foster exposure to bullying compared to others. They find that highly aggressive personalities, as well as individuals with high negative affectivity, are more often subject to bullying. ${ }^{20}$

We see that a long list of characteristics, both related to the individual and to the workplace, may influence whether the individual is exposed to workplace bullying. At the same time, these characteristics may be related to sickness absence. Failure to account for variables that affect both the propensity to be bullied and the outcome of interest will bias our results.

We utilize our access to the extremely rich Danish Registry Data. Our models control

\footnotetext{
${ }^{20}$ Aggressiveness is defined as the underlying trait that predisposes some individuals to attack more readily than others in response to environmental stimuli (Aquino and Bradfield, 2000). The fact that a person reacts more aggressively to threats might encourage retaliation by the other part. Negative affectivity refers to a unidimensional, pervasive disposition to experience high levels of distressing emotions such as anger, hostility, fear, or anxiety.
} 
for individual characteristics such as gender, age, education, ethnicity, and civil status. To minimize bias due to endogeneity, all conditioning variables are measured in the year prior to the survey (2005) or earlier. As mentioned above, previous literature points to the importance of personality traits, but, unfortunately, we do not have information on traits, such as negative affectivity, prior to observed bullying status. We do, however, have access to information on whether the individual has received any diagnoses of a mental or behavioral disorder through the Danish Psychiatric Central Register, which covers all contacts with the regional psychiatric treatment system prior to observed bullying. These diagnoses include, for example, depression, anxiety, schizophrenia, and attention deficit hyperactivity disorder (ADHD). Such cases can involve medical treatment without diagnosis. As a result, we include pre-2006 use of antidepressants and psycholeptics used to treat the diagnoses mentioned above. To our knowledge, no other study includes registry-based information on diagnoses and prescription drug use.

We also account for work-related factors such as tenure, sector, average earnings from 2001 to 2005, and working hours. In order to account for workplace-specific factors, we include a workplace fixed effect. This accounts for organizational traits that are constant within the firms in 2006, such as a particularly bad manager, high workloads, and industry. A workplace fixed effect further accounts for the gender ratio and overall level of sickness absence in the workplace. We include information on historic prescription drug use in terms of whether the individual has received any antidepressants and psycholeptics from 2001 to 2005, as well as the sum of weeks of sickness absence from 2001 to 2005. Finally, we control for pre-survey unemployment history, again measured by the sum of unemployment weeks from 2001 to 2005.

Table 3 presents the means and standard deviation of a selection of characteristics by bullying status. We see that targets of bullying differ from their non-bullied colleagues on most demographic characteristics. They are younger, more likely to be male, less likely to be married, and more likely to be divorced.

They also differ on a range of work-related characteristics. Targets have less tenure in the company and are more likely to be employed in the public sector. The individual's position in the company does not seem to matter for exposure to bullying. Unemployment history also differs by bullying status in that targets have a history of more weeks 
Table 3: Means and Standard Deviations of Characteristics by Bullying Status

\begin{tabular}{|c|c|c|c|c|c|c|}
\hline & \multicolumn{3}{|c|}{ Bullied } & \multicolumn{2}{|c|}{ Non-Bullied } & \multirow[b]{2}{*}{ No. Obs } \\
\hline & \multicolumn{2}{|c|}{ Mean } & Std. Dev. & Mean & Std. Dev. & \\
\hline \multicolumn{7}{|l|}{ Individual Characteristics $(\boldsymbol{X})$} \\
\hline Male $(0 / 1)$ & 0.425 & $* * *$ & 0.495 & 0.310 & 0.463 & 3182 \\
\hline Age & 42.158 & $* * *$ & 9.251 & 44.168 & 9.975 & 3182 \\
\hline Ethnicity $(0 / 1)$ & 0.079 & $* *$ & 0.270 & 0.041 & 0.198 & 3179 \\
\hline Married $(0 / 1)$ & 0.478 & $* * *$ & 0.501 & 0.666 & 0.472 & 3179 \\
\hline Cohabiting $(0 / 1)$ & 0.237 & $* * *$ & 0.426 & 0.134 & 0.341 & 3179 \\
\hline Single $(0 / 1)$ & 0.285 & $* * *$ & 0.452 & 0.200 & 0.400 & 3179 \\
\hline Divorced $(0 / 1)$ & 0.145 & $* * *$ & 0.353 & 0.086 & 0.281 & 3179 \\
\hline Children $0-2$ years $(0 / 1)$ & 0.092 & & 0.290 & 0.099 & 0.299 & 3179 \\
\hline Children $3-5$ years $(0 / 1)$ & 0.136 & & 0.344 & 0.123 & 0.328 & 3179 \\
\hline Children $6-10$ years $(0 / 1)$ & 0.206 & & 0.405 & 0.188 & 0.391 & 3179 \\
\hline Children $11-18$ years $(0 / 1)$ & 0.276 & & 0.448 & 0.270 & 0.444 & 3179 \\
\hline Years since Divorce & 1.039 & & 3.864 & 0.781 & 3.385 & 3179 \\
\hline Higher Education $(0 / 1)$ & 0.179 & & 0.384 & 0.151 & 0.358 & 3154 \\
\hline \multicolumn{7}{|l|}{ Work-Related Characteristics (W) } \\
\hline Tenure & 4.602 & $* * *$ & 4.995 & 7.757 & 7.436 & 3106 \\
\hline Full-time Employee $(0 / 1)$ & 0.978 & & 0.147 & 0.976 & 0.154 & 3179 \\
\hline Part-time Employee $(0 / 1)$ & 0.022 & & 0.147 & 0.024 & 0.154 & 3179 \\
\hline Private Sector $(0 / 1)$ & 0.351 & $* * *$ & 0.478 & 0.271 & 0.445 & 3177 \\
\hline Public Sector $(0 / 1)$ & 0.649 & $* * *$ & 0.478 & 0.729 & 0.445 & 3177 \\
\hline Top Management (0/1) & 0.018 & & 0.132 & 0.025 & 0.156 & 3179 \\
\hline Higher Management $(0 / 1)$ & 0.246 & & 0.431 & 0.225 & 0.418 & 3179 \\
\hline Medium Level Employment (0/1) & 0.294 & & 0.457 & 0.327 & 0.469 & 3179 \\
\hline Lower Level Employment (0/1) & 0.250 & & 0.434 & 0.274 & 0.446 & 3179 \\
\hline Other Employment $(0 / 1)$ & 0.184 & $* *$ & 0.389 & 0.136 & 0.343 & 3179 \\
\hline Unemployed $(0 / 1)$ & 0.009 & & 0.093 & 0.010 & 0.100 & 3179 \\
\hline Average Earnings 2001-2005 & 11.948 & & 1.817 & 12.084 & 1.473 & 3128 \\
\hline Weeks of Unemployment 2001-2005 & 12.807 & $* * *$ & 31.839 & 6.862 & 23.379 & 3182 \\
\hline \multicolumn{7}{|l|}{ Previous Health $(\boldsymbol{H})$} \\
\hline Weeks of Sick. Absence 2001-2005 & 2.610 & & 9.831 & 2.748 & 10.031 & 3182 \\
\hline Antidepressants 2001-2005 (0/1) & 0.114 & $*$ & 0.319 & 0.080 & 0.271 & 3182 \\
\hline Psycholeptics 2001-2005 (0/1) & 0.145 & & 0.353 & 0.117 & 0.321 & 3182 \\
\hline Mental or Behavioral Diag. $(0 / 1)$ & 0.057 & & 0.232 & 0.042 & 0.200 & 3182 \\
\hline Observations & & 228 & & & 2954 & \\
\hline
\end{tabular}

Notes: Means are tested against the mean of the non-bullied. ${ }^{* *}$ : Significant at a 1\% level. ${ }^{* *}$ : Significant at a $5 \%$ level. *: Significant at a $10 \%$ level. All variables are measured in 2005 unless stated otherwise. 
of unemployment than their non-bullied coworkers prior to 2006. In relation to information on pre-2006 sickness absence and health, we find that targets of bullying have less, though insignificant, sickness absence prior to $2006 .^{21}$ Mean values on the use of antidepressants and psycholeptics are higher for individuals exposed to bullying, but again the differences are only borderline significant for the use of antidepressant medication.

\subsubsection{Propensity to be a target of bullying}

We model the propensity to be exposed to workplace bullying with the following equation:

$$
\begin{aligned}
\text { Bullied }_{i w} & =\mathbf{1}\left[\mathbf{Z}_{i}^{\prime} \gamma+\nu_{w}+\epsilon_{i}>0\right], \quad \text { where } \\
\mathbf{Z} & =(\mathbf{X}, \mathbf{W}, \mathbf{H})
\end{aligned}
$$

where $\mathbf{X}$ is a vector of individual characteristics, $\mathbf{W}$ is a vector of work and employmentrelated characteristics, and $\mathbf{H}$ is a vector of previous health history. We include workplace fixed effects $\nu_{w}$. Equation (1) is estimated by a standard probit regression. Table 4 reports the marginal effects evaluated at the mean of the independent variables. In contrast to the implications of Table 3, once we condition on all the covariates and workplace fixed effects, we see that not many characteristics matter for the probability of being exposed to bullying. Being married and having more tenure decrease the probability of being a target. Being unemployed in 2005 makes you less likely to be bullied, compared to being a lower level employee, which indicates that people needs to be settled in the workplace to a certain extent in order to experience bullying.

In general, the workplace fixed effects seem to be of high importance. The joint significance test of the fixed effects is very high, indicating that there is something important going on within the workplaces related to bullying. While the data do not allow us to distinguish selection of individuals into workplaces from workplace characteristics, such as poor management, the questionnaire does contain an item on whether the respondent had previously been subject to bullying and if so, where. ${ }^{22}$ We use this item to construct

\footnotetext{
${ }^{21}$ Sickness absence for unemployed individuals is also registered in DREAM under the same rules that apply to public employees. In this case, the unemployment fund is considered their employer.

${ }^{22}$ The exact wording of the item is: "Have you previously been bullied?" and the response categories are: "No."; "Yes, in school."; "Yes, in a previous workplace."; "Yes, in the present workplace."; "Yes,
} 
Table 4: Probit Regression: Propensity To Be a Target of Bullying in the Workplace

\begin{tabular}{|c|c|c|c|}
\hline & \multicolumn{3}{|c|}{ Bullied } \\
\hline & \multicolumn{2}{|c|}{ Coef. } & \multirow[t]{2}{*}{ Std. Error } \\
\hline Individual Characteristics $(\boldsymbol{X})$ & & & \\
\hline Male (0/1) & 0.009 & & 0.010 \\
\hline Age & 0.000 & & 0.001 \\
\hline Divorce $(0 / 1)$ & 0.017 & & 0.025 \\
\hline Years since Divorce & -0.000 & & 0.002 \\
\hline Cohabiting (omit. var $=$ Single) & 0.017 & & 0.017 \\
\hline Married (omit. var = Single) & -0.039 & $* * *$ & 0.014 \\
\hline Ethnic $(0 / 1)$ & 0.020 & & 0.019 \\
\hline Higher Education (0/1) & 0.012 & & 0.013 \\
\hline Children $0-2$ years $(0 / 1)$ & -0.008 & & 0.015 \\
\hline Children $3-5$ years $(0 / 1)$ & 0.017 & & 0.016 \\
\hline Children 6 -10 years $(0 / 1)$ & 0.018 & & 0.012 \\
\hline Children $11-18$ years $(0 / 1)$ & 0.010 & & 0.012 \\
\hline \multicolumn{4}{|l|}{ Work-Related Characteristics (W) } \\
\hline Tenure & -0.003 & $* * *$ & 0.001 \\
\hline Full-time Employment (omit. var = Part-time) & -0.021 & & 0.045 \\
\hline Private Sector (omit. var $=$ Public) & 0.027 & & 0.053 \\
\hline \multicolumn{4}{|l|}{ Employment (omit. var $=$ Lower Level Employee) } \\
\hline Top Management & -0.025 & & 0.017 \\
\hline Higher Management & 0.018 & & 0.019 \\
\hline Medium Level Employee & 0.003 & & 0.013 \\
\hline Other Employment & -0.000 & & 0.018 \\
\hline Unemployed & -0.044 & $* * *$ & 0.014 \\
\hline Average Earnings 2001-2005 & 0.003 & & 0.003 \\
\hline Weeks of Unemployment 2001-2005 & 0.000 & $* *$ & 0.000 \\
\hline \multicolumn{4}{|l|}{ Previous Health $(\boldsymbol{H})$} \\
\hline Weeks of Sickness Absence 2001-2005 & -0.000 & & 0.000 \\
\hline Antidepressives 2001-2005 (0/1) & 0.019 & & 0.019 \\
\hline Psycholeptics 2001-2005 (0/1) & 0.011 & & 0.015 \\
\hline Mental or Behavioral Diagnosis $(0 / 1)$ & 0.021 & & 0.022 \\
\hline Workplace Fixed Effects & Yes & & \\
\hline Observations & 3182 & & \\
\hline Pseudo $R^{2}$ & 0.103 & & \\
\hline
\end{tabular}

Notes: Marginal effects are evaluated at the means of the dependent variables. Standard errors are clustered at the workplace level. ***: Significant at a $1 \%$ level. **: Significant at a $5 \%$ level. *: Significant at a $10 \%$ level. All variables are measured in 2005 unless stated otherwise. 
four different mutually exclusive groups: Never Bullied (NB); Newly Bullied (NWB); Always Bullied (AB); and Previously Bullied (PB). NWB comprises respondents who experience two or more NA in 2006 and who state that they have not previously been bullied, etc. ${ }^{23}$ If $\mathrm{PB}$ individuals are only bullied in their previous workplace, it suggests that bullying is a feature of the workplace. If, on the other hand, $\mathrm{AB}$ individuals are bullied in both a previous and current workplace, it suggests that bullying is due to individual characteristics. We find that $18 \%$ of $\mathrm{PB}$ and $27 \%$ of $\mathrm{AB}$ individuals report being bullied in a previous workplace while $8 \%$ of $\mathrm{PB}$ and $11 \%$ of $\mathrm{AB}$ report that they were previously bullied in their current workplace. This suggests that 1) leaving the workplace does not necessarily stop bullying and that 2) a significant amount of individuals stay in a workplace and bullying discontinues. It thus appears that a workplace can take measures to stop bullying. A regression of the number of shifts between workplaces in 2001 to 2006 for each of the four categories of bullying shows that bullied individuals have significantly more shifts than non-bullied individuals, and that AB individuals have significantly more shifts than PB individuals. ${ }^{24}$ Although we cannot observe whether a change of workplace was a result of being bullied, the results still imply that individuals change workplace until they find a place where they are not bullied. In section 6 , we will discuss plausible coping strategies, such as leaving one's workplace.

Taken together, the results demonstrate that both individual and workplace characteristics matter, and insofar that these have a direct effect on sickness absence, it is important to account for them in our subsequent analysis.

\section{Results}

This section starts by comparing the development in sickness absence of bullied and non-bullied employees around the survey period in order to address reasonable worries about reverse causality. We then present and estimate our model, gradually increasing our conditioning set. This allows us to investigate how the relationship between being exposed to bullying and long-term sickness absence depends on observable character-

${ }^{23}$ Note that the respondents answer to whether they have been bullied previously based on the definition of bullying (see section 2) and not according to the NAQ-R.

${ }^{24}$ Results available from the authors upon request.
} 
istics. Finally we investigate the heterogeneity of our results by splitting the sample according to gender.

\subsection{Measuring bullying and the development in weekly sickness ab- sence}

An important concern is whether individuals are being bullied due to their sickness absence, in which case we cannot rule out reverse causality. Figure 1 plots average longterm sickness absence for bullied and non-bullied individuals on a weekly basis. The bar shaded grey indicates the weeks in which individuals were surveyed. We do not observe a spike in sickness absence before the survey, which would give rise to concerns about reverse causality. It does seem as if the targets of bullying have slightly more sickness absence prior to the survey, but recall that they are asked about NA within the past six months. We would therefore expect to see some differences in sickness absence prior to the survey period. ${ }^{25}$ Figure 1, however, may also imply that there is little

Figure 1: Weekly Average Long-term Sickness Absence by Bullying Status in 2006

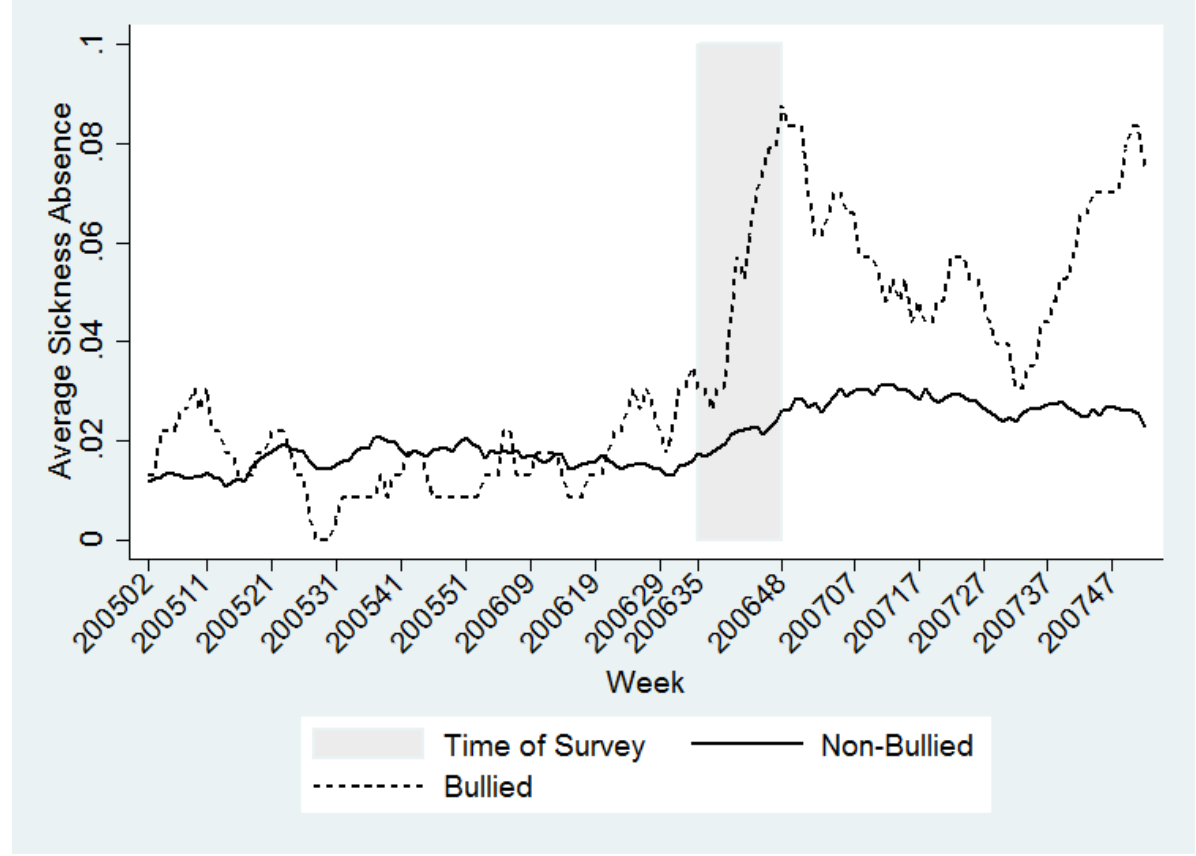

\footnotetext{
${ }^{25}$ As mentioned above employment may be an issue in that there are less incentives to register absence for unemployed individuals which is why we reconstruct Figure 1 conditioning on being in employment. The figure is practically unchanged, further emphasizing that employment is not an issue for this analysis. It is available from the authors upon request.
} 
or no persistence in bullying, or at least that the individuals who had previously been exposed to bullying did not experience higher levels of sickness absence. As our sample is implicitly conditioned on being employed in the weeks of the survey in 2006, it is conceivable that the people hurt most by bullying in the past will not be in the sample. As mentioned above, the questionnaire includes an item asking whether the respondent had previously been subject to bullying. A mean comparison of the targets and nontargets shows that targets were no more likely to have been bullied previously than non-targets, suggesting that persistence is not a big issue in this sample. We also exploit the item to create the four groups $\mathrm{AB}, \mathrm{NWB}, \mathrm{PB}$ and $\mathrm{NB}$, as described in subsection 3.3.1. Figure 2 replicates Figure 1 using the new definitions of exposure to bullying.

Figure 2: Weekly Average Long-term Sickness Absence by Bullying Status in 2006

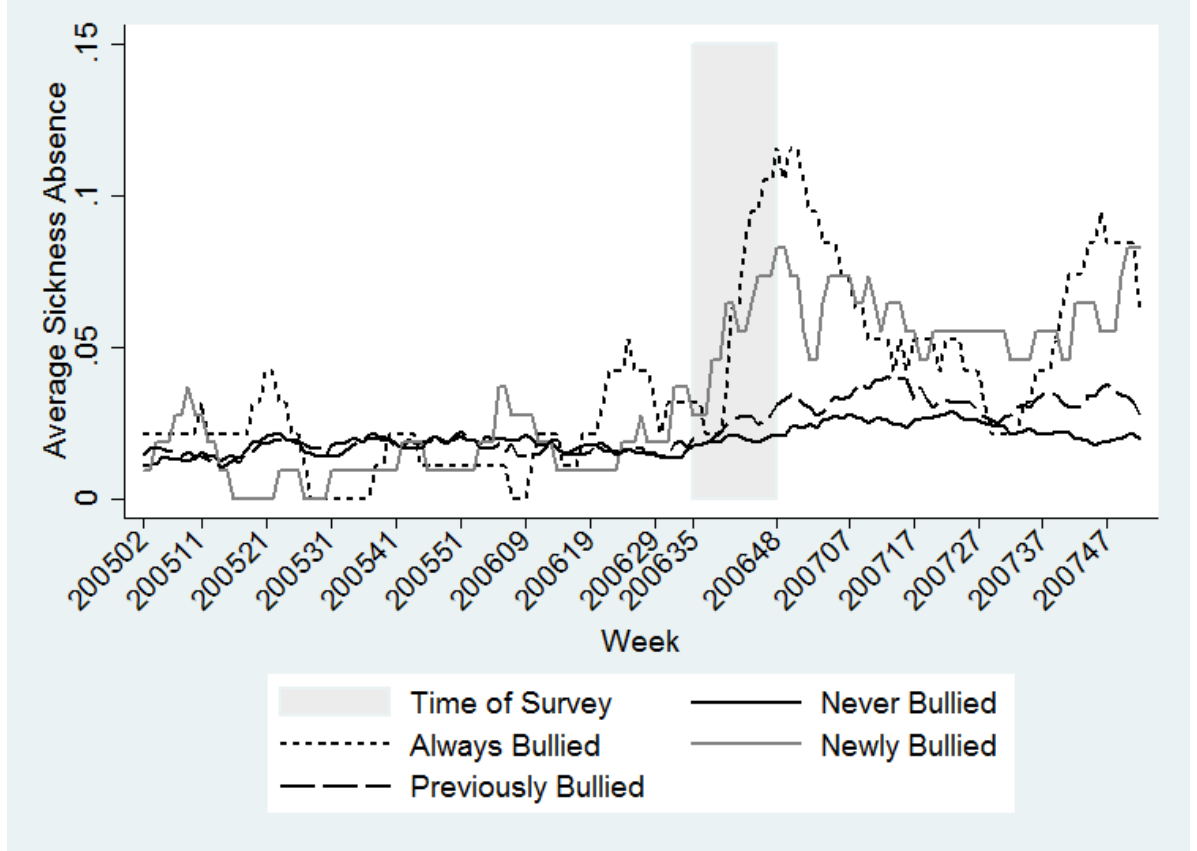

There does not appear to be a significant difference in sickness absence between NB and PB individuals. ${ }^{26}$ The development in sickness absence is more volatile for NWB and

\footnotetext{
${ }^{26}$ A raw mean comparison shows that between 2001 and 2008, PB individuals only have significantly more absence compared to NB individuals in 2002 (Coef. equals 0.33 weeks). Furthermore $73 \%$ of PB individuals indicate that the bullying happened in school. This could explain why we do not observe a higher level of sickness absence for this group (except in 2002) compared to NB individuals (The table can be found in D).
} 
$\mathrm{AB}$ individuals, probably due to the smaller sample size (95 individuals are identified as AB and 109 individuals as NWB), but before 2006 they fluctuate around the same mean as the NB and PB individuals. ${ }^{27}$ After 2006, we see a spike, which is larger for AB than NWB individuals. This could reflect that recurring exposure to bullying is more harmful. ${ }^{28}$ Again, the findings suggest that we need not worry about the persistence of bullying.

Another concern is that being asked about bullying may cause people to call in sick. By Figure 1 we cannot rule out that this is the case. We do, however, find it highly implausible that merely asking individuals about bullying leads to the large persistence in sickness absence that Figure 1 shows. Recall that Figure 1 only contains spells of sickness absence with a total duration of more than three weeks.

\subsection{The relationship between bullying and sickness absence: Account- ing for observable characteristics}

Table 1 and Figure 1 indicate that targets of bullying experience significantly more longterm sickness absence than their non-bullied colleagues. Other factors that influence both exposure to bullying and sickness absence, however, may explain this relationship, as mentioned above. In order to take these factors into account, we estimate the relationship between workplace bullying and long-term sickness absence using ordinary least squares (OLS) estimation, gradually expanding the conditioning set in the regressions. The regression can be summarized by the following equation:

$$
\begin{aligned}
y_{i w} & =\mathbf{Z}_{i}^{\prime} \gamma+\beta^{\prime} \text { Bullied }+\nu_{w}+\epsilon_{i}, \quad \text { where } \\
\mathbf{Z} & =(\mathbf{X}, \mathbf{W}, \mathbf{H}) .
\end{aligned}
$$

\footnotetext{
${ }^{27}$ Comparing raw means, we find no significant differences in absence between NWB and NB before 2007. Comparing AB to NB, absence is slightly higher for the AB individuals. However, all differences are insignificant prior to 2006. See D.

${ }^{28}$ The conclusions are robust to the alternative specification of exposure to bullying where we only compare NWB to NB individuals. However, unlike in our main results (presented below), the relationship now only persists for two years (2007 and 2008). We also restrict the sample to new employees (individuals who changed workplace between 2005 and 2006) since previous bullying should be less of an issue for this subsample. Again, our conclusions are robust to this specification, and we now find that the persistence in sickness absence appears to be even more widespread. Results available from the authors upon request.
} 
$y_{i w}$ refers to sickness absence from 2007 to 2011 of individual $i$ in workplace $w$. Bullied is an indicator for being a target of workplace bullying and the coefficient $\beta$ is our parameter of interest. $\beta$ captures everything happening between our identification of being a target of bullying in 2006 up until the year in which the outcome is measured. As a result we cannot distinguish whether the relationship is due to lasting scares or because bullying causes bullying. $\mathbf{Z}$ is the rich set of conditioning variables mentioned in section 3.3 and $\nu_{w}$ is a workplace fixed effect. We begin by estimating the relationship between bullying and the outcome excluding any confounders. Next, we include the individual characteristics $\mathbf{X}$. This conditioning set resembles what is most often available to researchers through registries. We then expand $\mathbf{Z}$ to also include registry information on labor market history and employment related characteristics $\mathbf{W}$, as well as workplace fixed effects $\nu_{w}$. Finally we include pre-2006 sickness absence, prescription drug use, and diagnosis of a behavioral or mental disorder $\mathbf{H}$ in the conditioning set. Again, note that all conditioning variables are measured in 2005 or earlier.

According to the results presented in Table 5, targets of workplace bullying have a significantly higher level of long-term sickness absence than their non-bullied colleagues in the first three years after we observe bullying. The relationship fades away and is completely gone in 2011. The results are only affected, to a minor extent, by the expansion of the conditioning set, which means that they are not driven by certain individual characteristics, pre-2006 sickness absence, poor management, or a bad company culture at the workplace, previous use of antidepressant medication, or even a diagnosis of mental or behavioral disorder.

The estimates are also significant in an economic sense. The final model suggests that being exposed to workplace bullying in 2006 increases long-term sickness absence in 2007-2009 by about 1.3 weeks. In other words, individuals exposed to bullying have more than twice the sickness absence than their non-bullied colleagues.

Since 2010, employers are required to speak with employees who are off sick within the first four weeks of absence. Primarily, the purpose of this talk is first of all to provide the local authority with information regarding the absence and to talk about how best to tackle the situation to facilitate a quick return to work. The employee is not required to submit a doctor's note, but the employer may ask for it (for Labour Market and 
Table 5: OLS Results: Workplace Bullying and Sickness Absence

\begin{tabular}{|c|c|c|c|c|c|c|c|c|}
\hline \multirow{3}{*}{ Bullied $(0 / 1)$} & \multicolumn{8}{|c|}{ Weeks of Long-term Sickness Absence (Year) } \\
\hline & \multicolumn{2}{|l|}{2007} & \multicolumn{2}{|c|}{2008} & 2009 & \multicolumn{2}{|c|}{2010} & 2011 \\
\hline & 1.316 & ** & 1.459 & ** & 1.266 & ** & 0.896 & 0.643 \\
\hline Std. Error & $(0.584)$ & & $(0.558)$ & & $(0.546)$ & & $(0.557)$ & $(0.445)$ \\
\hline \multicolumn{9}{|c|}{ + Individual Char. $(\boldsymbol{X})$} \\
\hline Bullied $(0 / 1)$ & 1.422 & $* *$ & 1.601 & $* * *$ & 1.346 & $* *$ & 0.896 & 0.646 \\
\hline Std. Error & $(0.593)$ & & $(0.559)$ & & $(0.554)$ & & $(0.564)$ & $(0.475)$ \\
\hline \multicolumn{9}{|c|}{ + Workrelated Char. (W) } \\
\hline Bullied (0/1) & 1.366 & $* *$ & 1.490 & $* * *$ & 1.374 & $* *$ & 0.905 & 0.561 \\
\hline Std. Error & $(0.613)$ & & $(0.554)$ & & $(0.571)$ & & $(0.588)$ & $(0.485)$ \\
\hline \multicolumn{9}{|c|}{ + Previous Health $(\boldsymbol{H})$} \\
\hline Bullied (0/1) & 1.262 & $* *$ & 1.389 & $* *$ & 1.284 & $* *$ & 0.854 & 0.508 \\
\hline Std. Error & $(0.604)$ & & $(0.546)$ & & $(0.547)$ & & $(0.577)$ & $(0.489)$ \\
\hline Observations & 3182 & & & & & & & \\
\hline
\end{tabular}

Notes: The standard errors are clustered at the workplace level. ${ }^{* * *}$ : Significant at a $1 \%$ level.

**: Significant at a $5 \%$ level. *: Significant at a $10 \%$ level. E presents the full

set of estimates for the final model.

Recruitment, 2010). Similar to Ose (2005), we expect our observed sickness absence to reflect actual absence due to illness. In section 6 , we will discuss, however, that bullying affects the individual's health as an explanation of why absence increases.

\subsection{Gender heterogeneity}

We investigate the heterogeneity of the results by splitting the sample by gender. ${ }^{29}$ There is no reason to believe that men and women will react similarly when experiencing workplace bullying, and it is not obvious that the different characteristics will affect the exposure to bullying in the same way across genders. For instance, a highly educated man may induce respect, whereas a highly educated woman may be seen as a threat (Derks et al., 2011). Table 6 presents the results of the separate regressions for the male and female sample. We now only observe a positive and significant correlation between bullying and sickness absence for women from 2007 to 2009. Excluding any other explanatory variables from the regressions, women exposed to bullying have, on average, 2.3 weeks more of long-term sickness absence than their non-bullied female

\footnotetext{
${ }^{29}$ However, we cannot reject the Chow test of equal coefficients for men and women.
} 
colleagues in 2007. Including the full conditioning set only reduces this results by 0.13 weeks, equal to about one day. If we compare this to an average of 1.6 weeks of longterm sickness absence for non-bullied women, bullying more than doubles the amount of absence. If we apply the cost elasticity on the duration of long-term spells of absence for women found in Johansson and Palme (2005), our results imply that reducing the probability of being bullied by $50 \%$ corresponds to an increase in the cost of sickness absence of 5\%. Ziebarth and Karlsson (2014) obtain a similar elasticity, their findings showing that an increase in the replacement rate from 80 to $100 \%$ increased the number of sickness days by $20 \%$ for the compliers.

As before, the relationship is persistent but now only significant at a $10 \%$ level in 2009. Before, the size of the estimates was constantly equal to 1.2 weeks from 2007 to 2009 but now appears to decrease by about one day per year. In contrast to the results for women, we observe no significant differences for men. The coefficients are small, and they are only slightly affected by the expansion of the conditioning set. This suggests that the lack of relationship is not merely due to the small sample size. Men apparently do not seem to have more long-term sickness absence when exposed to bullying.

A possible explanation for the gender differences in the results is that men and women are exposed to different bullying behavior. A thorough investigation of the type and frequency of the NA shows that men are exposed to more NA than women and at a higher frequency. When the sample is divided into work-related, person-related, and physically intimidating bullying, men are at least as likely to be exposed to work and person-related bullying and more likely to be physically intimidated. ${ }^{30}$

Observe also that the relationship for women disappears after three years. There are different explanations for this. Either bullying is dealt with, or the composition of workers in the workplace has changed such that either the target or the perpetrator(s) do not work together anymore. This is very plausible in Danish workplaces, as more than $50 \%$ of employees in this sample have left their workplace after four years. We will return to turnover below.

According to the propensity score in subsection 3.3.1, gender does not explain exposure to bullying once we include workplace fixed effects. It also appears as if men and

\footnotetext{
${ }^{30}$ Results available from the authors upon request.
} 
Table 6: OLS Results: Workplace Bullying and Sickness Absence By Gender

\begin{tabular}{|c|c|c|c|c|c|c|c|c|}
\hline \multirow{3}{*}{ Female Sampl } & \multicolumn{8}{|c|}{ Weeks of Long-term Sickness Absence (Year) } \\
\hline & \multirow[t]{2}{*}{2007} & \multicolumn{3}{|c|}{2008} & \multicolumn{2}{|c|}{2009} & \multirow[t]{2}{*}{2010} & \multirow[t]{2}{*}{2011} \\
\hline & & & & & & & & \\
\hline Bullied $(0 / 1)$ & 2.261 & $* *$ & 2.086 & $* *$ & 1.986 & $* *$ & 1.261 & 1.257 \\
\hline Std. Error & $(0.919)$ & & $(0.857)$ & & $(0.921)$ & & $(0.812)$ & $(0.758)$ \\
\hline \multicolumn{9}{|c|}{ + Individual Char. $(\boldsymbol{X})$} \\
\hline Bullied $(0 / 1)$ & 2.333 & $* *$ & 2.107 & $* *$ & 1.969 & $* *$ & 1.213 & 1.269 \\
\hline Std. Error & $(0.943)$ & & $(0.852)$ & & $(0.922)$ & & $(0.814)$ & $(0.772)$ \\
\hline \multicolumn{9}{|c|}{ + Work-related Char. (W) } \\
\hline Bullied (0/1) & 2.281 & $* *$ & 2.037 & $* *$ & 1.844 & $*$ & 1.093 & 1.232 \\
\hline Std. Error & $(0.934)$ & & $(0.871)$ & & $(0.974)$ & & $(0.887)$ & $(0.819)$ \\
\hline \multicolumn{9}{|c|}{+ Previous Health $(\boldsymbol{H})$} \\
\hline Bullied (0/1) & 2.135 & $* *$ & 1.941 & $* *$ & 1.735 & $*$ & 1.037 & 1.171 \\
\hline Std. Error & $(0.923)$ & & $(0.871)$ & & $(0.944)$ & & $(0.864)$ & $(0.813)$ \\
\hline Observations & 2169 & & & & & & & \\
\hline \multicolumn{9}{|c|}{ Male Sample } \\
\hline Bullied (0/1) & 0.182 & & 0.729 & & 0.447 & & 0.524 & -0.105 \\
\hline Std. Error & $(0.632)$ & & $(0.674)$ & & $(0.581)$ & & $(0.582)$ & $(0.758)$ \\
\hline \multicolumn{9}{|c|}{ + Individual Char. $(\boldsymbol{X})$} \\
\hline Bullied (0/1) & 0.206 & & 0.798 & & 0.433 & & 0.544 & -0.183 \\
\hline Std. Error & $(0.631)$ & & $(0.662)$ & & $(0.569)$ & & $(0.621)$ & $(0.772)$ \\
\hline \multicolumn{9}{|c|}{ + Workrelated Char. (W) } \\
\hline Bullied (0/1) & 0.448 & & 0.715 & & 0.564 & & 0.570 & -0.321 \\
\hline Std. Error & $(0.755)$ & & $(0.735)$ & & $(0.685)$ & & $(0.560)$ & $(0.819)$ \\
\hline \multicolumn{9}{|c|}{+ Previous Health $(\boldsymbol{H})$} \\
\hline Bullied (0/1) & 0.317 & & 0.564 & & 0.471 & & 0.517 & -0.350 \\
\hline Std. Error & $(0.724)$ & & $(0.717)$ & & $(0.646)$ & & $(0.537)$ & $(0.813)$ \\
\hline Observations & 1013 & & & & & & & \\
\hline
\end{tabular}

Notes: The standard errors are clustered at the workplace level. ${ }^{* * *}$ : Significant at a $1 \%$ level. **: Significant at a $5 \%$ level. *: Significant at a $10 \%$ level. The full set of estimates is available from the authors upon request. 
women are exposed to the same type of bullying behavior. Still, our results show that being bullied at work only significantly increases long-term sickness absence for women and not for men. These results point toward that 1) the health of men and women are affected differently or that 2) they employ different coping strategies when exposed to workplace bullying. See, for example, Kristofferzon et al. (2003), who find that men often want to go back to work when they are recovering from health problems, whereas women need more time at home.

In order to understand why the differences in sickness absence emerge, we investigate the relationship between bullying, health, turnover, and labor force attachment in section 6. First, however, we conduct a series of robustness checks on the results above.

\section{Robustness}

In the previous section, we showed that our results are robust to the inclusion of an extensive conditioning set. In order to further increase our confidence in the results, we conduct a series of additional robustness checks. We add plausible confounders such as personality and work environment characteristics. These robustness checks are reported for the female employees as the results presented above were still not significant for male employees when expanding the conditioning set to include variables on personality and the working environment. ${ }^{31}$ In all models, we condition on the full set of individual and work-related characteristics, workplace fixed effects, and pre-2006 health.

\subsection{Personality characteristics}

As mentioned previously, personality characteristics are likely to affect whether a person is subject to bullying and the individual's level of sickness absence. Previous studies have, for example found positive correlations between personality traits such as negative affectivity and workplace bullying (Aquino and Bradfield, 2000). People with high negative affectivity view themselves and aspects of the world negatively. Negative affectivity roughly corresponds to the personality factor of anxiety/neuroticism from the Big Five personality traits questionnaire. Positive affectivity, on the other hand, refers to how

\footnotetext{
${ }^{31}$ We find that in 2011 at a $10 \%$ significance level, men who are subject to bullying have one less sickday when including all work environment variables.
} 
people experience positive emotions and roughly corresponds to the extraversion personality factor (Costa and McCrae, 1980). Both measures of affectivity are believed to be fairly stable over time, and having high negative affectivity does not imply low positive affectivity or vice versa (Watson and Clark, 1984). The questionnaire contains the Positive and Negative Affect Schedule (PANAS) measuring negative and positive affectivity by asking individuals to what extent they have experienced 20 different emotions within the past four weeks (Watson et al., 1988). ${ }^{32}$ The questionnaire also contains Setterlind and Larsson's (1995) Sense of Coherence (SOC) scale, which measures to what extent people believe events happen to them by intent or chance. This is important in relation to coping strategies. If people do not believe that they can change the course of an event, they are probably less likely to try. We measure SOC using nine different items. ${ }^{33}$ We do not include the personality measures in our main specification as they are likely to be affected by exposure to bullying as everything is measured simultaneously in the questionnaire. Affectivity is believed to be a stable trait, but the questionnaire asks about feelings experienced within the past four weeks which we believe are likely to be affected by exposure to bullying.

All three factors are extracted through confirmatory principal component analysis, and scores are obtained using the regression method. Table 7 reports the results of our preferred specification and the results when extending the conditioning set to include all three personality characteristics. We see that the size of the estimates is slightly reduced when conditioning on personality characteristics, but they remain significant at a $10 \%$ level in 2007 and a $5 \%$ level in 2008. When significant, the coefficients on the personality characteristics have the expected sign: positive affectivity is negative, negative affectivity is positive, and SOC is only marginally significant and positive in 2011 (results not shown here).

\footnotetext{
${ }^{32}$ We exclude one item "Alert," as it loads on negative affectivity instead of positive affectivity, in contrast to the original scale. Cronbach's alpha on negative affectivity is 0.88 , and 0.87 on positive affectivity, indicating excellent internal validity. F contains loadings and Cronbach's alphas.

${ }^{33}$ Cronbach's alpha on SOC is 0.78 .
} 
Table 7: OLS Results: Personality, Workplace Bullying and Sickness Absence Female Employees

\begin{tabular}{|c|c|c|c|c|c|c|c|}
\hline & \multicolumn{7}{|c|}{ Weeks of Long-term Sickness Absence (Year) } \\
\hline & 2007 & & 2008 & & 2009 & 2010 & 2011 \\
\hline \multicolumn{8}{|l|}{ Main Conditioning Set } \\
\hline Bullied $(0 / 1)$ & 2.135 & $* *$ & 1.941 & $* *$ & 1.735 & 1.037 & 1.171 \\
\hline Std. Error & $(0.923)$ & & $(0.871)$ & & $(0.944)$ & $(0.864)$ & $(0.813)$ \\
\hline \multicolumn{8}{|l|}{ + Personality } \\
\hline Bullied $(0 / 1)$ & 1.770 & $*$ & 1.927 & $* *$ & 1.500 & 0.543 & 0.993 \\
\hline Std. Error. & $(0.928)$ & & $(0.887)$ & & $(0.966)$ & $(0.814)$ & $(0.793)$ \\
\hline Observations & 2169 & & & & & & \\
\hline
\end{tabular}

\subsection{Work environment characteristics}

The questionnaire also contains a wide variety of items related to various aspects of the working environment. As mentioned previously, a vast amount of work environment characteristics has been considered as antecedents of bullying. In addition, they may independently affect sickness absence. The items in the survey come from the Copenhagen Psychosocial Questionnaire (COPSOQ II) (Pejtersen et al., 2010), which was developed to measure the psychosocial work environment among Danish employees. The factors are extracted using confirmatory factor analysis on the COPSOQ II scales and then grouped as proposed in Pejtersen et al. (2010). The validity of the factors is assessed by Cronbach's alpha. All alphas range between 0.535 and $0.878 .{ }^{34}$ Table 8 summarizes the results. Again, we see that the results are robust to the expansion of the conditioning set. In 2007 , the coefficient on bullying is only significant at a $10 \%$ level after adjusting for job content. It remains significant at a $10 \%$ level after including additional controls. The results in 2008 are not affected by the inclusion of the workplace characteristics. We stress that caution should be exercised when interpreting these results as we believe that characteristics like "perception of the manager", "trust in colleagues", "meaning", and "loyalty" are likely to be affected by the exposure to bullying. Nevertheless, our results

\footnotetext{
${ }^{34}$ See $\mathrm{F}$ for the full set of scales, Cronbach's alphas, and loadings.
} 
are, to a large extent, robust to the inclusion of work environment characteristics.

The robustness checks support our previous findings. Being exposed to workplace bullying is associated with increases in long-term sickness absence for women even when conditioning on personality and work environment characteristics. ${ }^{35}$ The next section discusses different explanations as to why we find a relationship for women and not for men.

\section{$6 \quad$ Health and coping strategies}

The results above show that being exposed to workplace bullying increases sickness absence for women but not for men. If bullying deteriorates health, we would expect equal effects for men and women, but this is not what we find. A plausible explanation is that men and women have different coping strategies. It may be the case that men leave the workplace, whereas women stay, or men attend work even though they feel sick. A third explanation could be a greater tendency among men to shirk. We can identify this type of behavior in our subsample of public employees, insofar that shortterm absence can be viewed as shirking behavior, as described in Ose (2005). The relevant question is thus whether bullying affects health differently for men and women or whether the results reflect different coping strategies for men and women. In this section, we discuss the following possible explanations: health, short-term sickness absence or shirking behavior, presenteeism, turnover, employment, and labor force participation. As before, regressions are performed controlling for the main conditioning set, including individual characteristics, work-related characteristics, workplace fixed effects, and pre2006 health.

\subsection{Health measures}

The questionnaire allows us to address an immediate measure of the respondent's health, which cannot be obtained through the registries. Respondents were asked to assess their

\footnotetext{
${ }^{35}$ The results are also robust to previous exposure to bullying for both men (insignificant) and women. We do not know, however, exactly when bullying occurred, and it could be the case that the previous episode actually reflects the current episode. Furthermore, the results for men (insignificant) and women are robust to the inclusion of indicator variables for being underweight, normal weight, overweight, and extremly overweight (defined by body mass index) measured in 2006. Results available from the authors upon request.
} 
Table 8: OLS Results: Work Environment Characteristics, Workplace Bullying and Sickness Absence

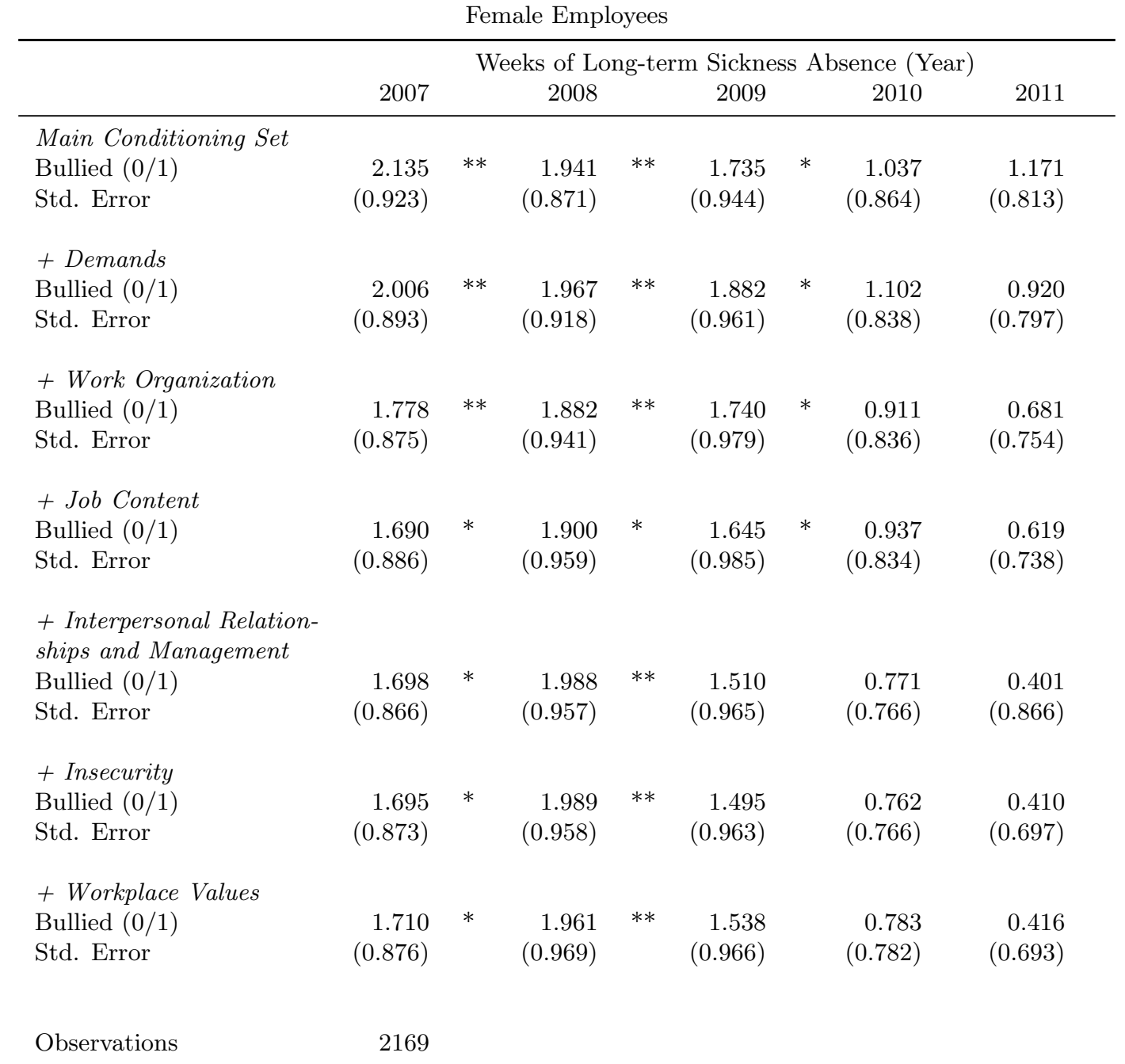

Notes: The main conditioning set includes individual and work-related characteristics and previous health. The standard errors are clustered at the workplace level. ***: Significant at a $1 \%$ level. **: Significant at a $5 \%$ level. *: Significant at a $10 \%$ level. The full set of estimates is available from the authors upon request. 
overall health: "How good do you find your health?", which is measured on a five-point Likert scale and recoded on a scale from one to five, five indicating excellent health. In this case, we are faced with common concerns when using self-reported measures, such as common source bias and reverse causality, and we stress that the results should be interpreted with caution. We still believe, however, that a subjective measure may provide additional information as objective measures may not reflect whether the person actually feels hampered due to health issues.

From the registry data, we obtain information on prescription drug use and diagnoses. As mentioned above, bullying has been positively related to anxiety and depression in a number of studies (e.g. Nielsen and Einarsen, 2012). We construct two dummy variables: antidepressants are equal to one if the respondent purchased antidepressant medication (Anatomical Therapeutic Chemical (ATC) Classification System code N06A), and psycholeptics are equal to one if the individual purchased psycholeptics (ATC code N05) between 2007 and 2011. Psycholeptics are usually used in the treatment of neuroses and psychosomatic disorders related to anxiety and tension. Finally we construct a dummy variable indicating whether the respondent had been diagnosed with a mental or behavioral disorder five years after we observe bullying (International Classification of Diseases (ICD-10) code F). ${ }^{36}$

Table 9 shows that targets of bullying report worse self-rated health than non-bullied colleagues, and men seem to report health at least as bad as women's. However, bullied men do not tend to receive more antidepressant medication or psycholeptics or to be diagnosed with a mental or behavioral disorder by 2011 compared to non-bullied men. Bullied men thus have worse immediate health than their non-bullied coworkers, but this difference is not observed in the health variables measured through the registries, suggesting that health consequences for men are temporary or that they cope with the issues themselves and do not involve general practitioners. For women, we only see significant differences in the use of antidepressants. Women exposed to bullying are more likely to use antidepressants than their non-bullied colleagues. Women's health thus seems to suffer both in the short and long-run when exposed to bullying.

\footnotetext{
${ }^{36}$ We constructed two other variables, a depression diagnosis variable and an anxiety diagnosis variable. Cases of these diagnoses in the data, however, were limited to 13 cases each out of the 3182 respondents in 2007. Results were therefore not reliable and hence not reported.
} 
Table 9: OLS Results: Workplace Bullying and Health Mechanisms

\begin{tabular}{|c|c|c|c|c|c|c|}
\hline & \multicolumn{2}{|c|}{$\begin{array}{l}\text { Selfrated } \\
\text { Health }\end{array}$} & \multicolumn{2}{|c|}{$\begin{array}{c}\text { Antidepressants } \\
(0 / 1)\end{array}$} & $\begin{array}{c}\text { Psycholeptics } \\
(0 / 1)\end{array}$ & $\begin{array}{c}\text { Mental or Behav. } \\
\text { Diag. } 2011\end{array}$ \\
\hline \multicolumn{7}{|c|}{ Female Sample } \\
\hline \multicolumn{7}{|c|}{ Main Conditioning Set } \\
\hline Bullied $(0 / 1)$ & -0.291 & $* * *$ & 0.067 & $* *$ & 0.001 & -0.014 \\
\hline Std. Error & $(0.087)$ & & $(0.033)$ & & $(0.038)$ & $(0.016)$ \\
\hline Observations & 2162 & & 2169 & & 2169 & 2169 \\
\hline Mean & 3.599 & & 0.122 & & 0.153 & 0.039 \\
\hline \multicolumn{7}{|l|}{ Male Sample } \\
\hline \multicolumn{7}{|c|}{ Main Conditioning Set } \\
\hline Bullied $(0 / 1)$ & -0.403 & $* * *$ & 0.024 & & 0.011 & 0.033 \\
\hline Std. Error & $(0.114)$ & & $(0.032)$ & & $(0.030)$ & $(0.025)$ \\
\hline Observations & 1002 & & 1013 & & 1013 & 1013 \\
\hline Mean & 3.59 & & 0.083 & & 0.114 & 0.036 \\
\hline
\end{tabular}

\subsection{Public sector employees}

In the main analysis, we were only able to consider long-term sickness absence since spells below three weeks are not recorded in DREAM for private sector employees. ${ }^{37}$ For public sector employees we are able to observe absence from day one. We use this subsample of employees to investigate two issues. Figure 3 plots average weekly sickness absence (both long and short-term absence) for public employees. One potential concern in Figure 1 is that being exposed to workplace bullying is driven by many short-term spells of absence, which would indicate potential problems with reverse causality. If this is the case, this graph would pick it up. Figure 3 is very similar to Figure 1. Thus, short-term sickness spells of absence do not seem to drive bullying, at least in the public sector.

Second, we use the sample to investigate whether short-term absence is used as a coping strategy. It is conceivable that the reason we do not observe any increase in long-term sickness absence for the subsample of men is that they are more likely to have short-term absence spells, thus allowing them to cope with bullying. As a result, we run our regressions on the restricted sample of public sector employees. The outcome is now

\footnotetext{
${ }^{37}$ This is due to a liability payment period for private companies in Denmark for the first three weeks of sickness absence.
} 
Figure 3: Weekly Average Sickness Absence by Bullying Status in 2006 Public Sector Employees

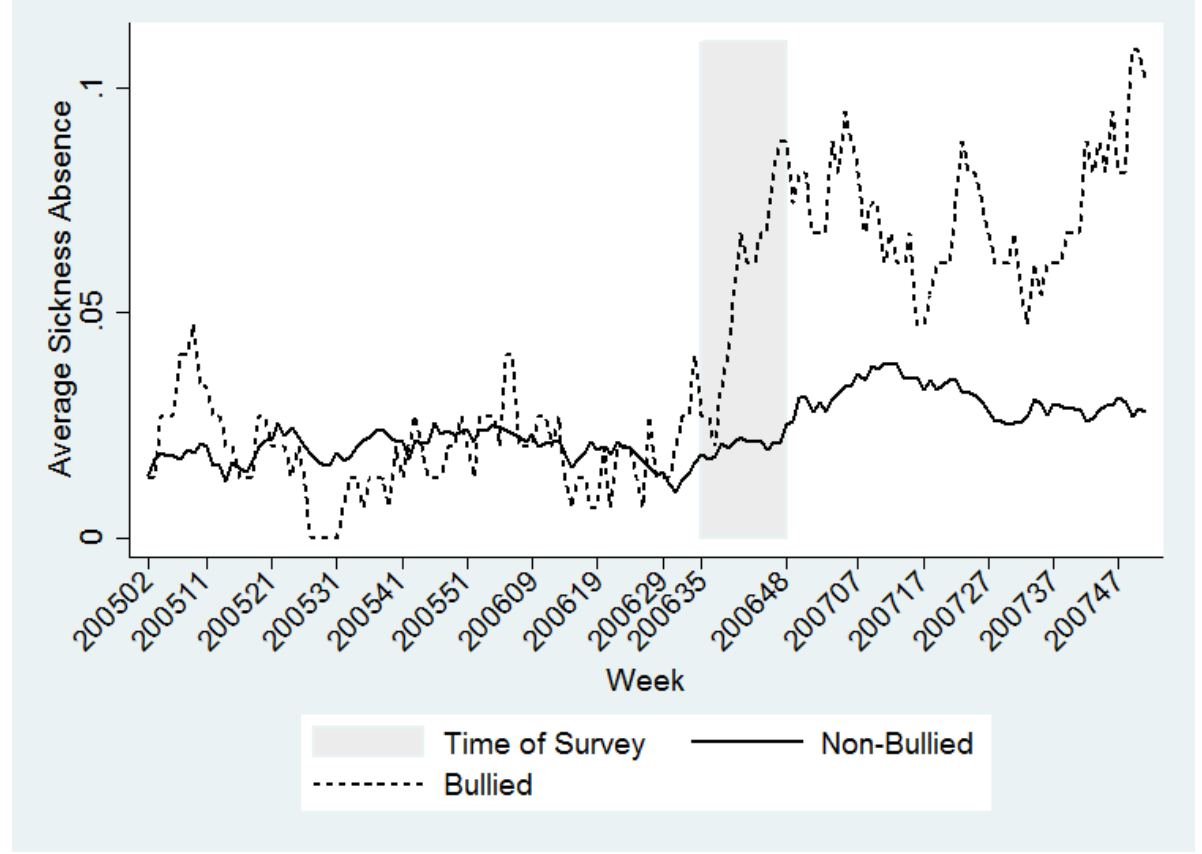

sickness absence weeks measured from week one and contains both short and long-term spells. Table 10 reports these results.

Targets of bullying employed in the public sector have, on average, two weeks more absence than non-bullied public sector employees. As found previously, these results are persistent for two years before gradually decreasing. The results are thus robust to the inclusion of short-term absence. In terms of magnitude, the estimates are slightly larger compared to the estimates using the full sample, but this is due to public sector employees having more long-term sickness absence than private sector employees. When we run the regressions on short-term absence (spells $<2$ weeks), we find no difference among targets and non-bullied coworkers for men and women. ${ }^{38}$ A priori one would think that bullying would lead to an initial level of discomfort and an increased level of short-term sickness absence before accelerating into a higher level of impairment and long-term absence. According to the results, this does not appear to be the case. Based on conservation of resources theory, Conway et al. (2016) argue that targets of bullying

\footnotetext{
${ }^{38}$ Results available from the authors upon request.
} 
may refrain from taking sick leave in order to avoid being subject to further harassment as a consequence of the leave. Bullied individuals may choose to go to work until their health deteriorates to such an extent that long-term sickness absence is a last resort. This theory is related to presenteeism, which we will discuss below.

Our results further support Ose's (2005) theoretical model. She argues that a bad work environment affects health and therefore only long-term and not short-term sickness absence, as long-term absence should reflect actual health impairment, whereas shortterm absence is likely to reflect shirking behavior. In Denmark, individuals who are away from work due to long-term illness are in contact with the workplace on a regular basis, and the employer can ask for a doctor's note in which case they would catch shirking behavior, whereas short-term absence is not monitored. Consequently, if being exposed to workplace bullying increases shirking behavior, we expect to see differences in short-term and not in long-term sickness absence, which is not the case.

Table 10: OLS Results: Workplace Bullying and Sickness Absence Public Sector Employees

\begin{tabular}{|c|c|c|c|c|c|c|c|}
\hline & \multicolumn{7}{|c|}{ Weeks of Sickness Absence (Year) } \\
\hline & 2007 & & 2008 & & 2009 & 2010 & 2011 \\
\hline \multicolumn{8}{|c|}{ Main Conditioning Set } \\
\hline Bullied (0/1) & 1.938 & $* *$ & 2.127 & $* *$ & 1.427 & 0.543 & 0.313 \\
\hline Std. Error & $(0.928)$ & & $(0.849)$ & & $(0.767)$ & $(0.699)$ & $(0.595)$ \\
\hline Observations & 2298 & & & & & & \\
\hline \multicolumn{8}{|l|}{ Women } \\
\hline Bullied (0/1) & 2.445 & $* *$ & 2.577 & $* *$ & 1.649 & 0.981 & 0.775 \\
\hline Std. Error & $(1.203)$ & & $(1.065)$ & & $(1.009)$ & $(0.973)$ & $(0.802)$ \\
\hline Observations & 1776 & & & & & & \\
\hline \multicolumn{8}{|l|}{ Men } \\
\hline Bullied (0/1) & 0.838 & & 1.050 & & 0.619 & -0.853 & -1.193 \\
\hline Std. Error & $(1.312)$ & & $(1.223)$ & & $(0.722)$ & $(0.530)$ & \\
\hline Observations & 522 & & & & & & \\
\hline
\end{tabular}




\subsection{Presenteeism}

More recently, psychologists and sociologists have addressed the phenomenon of presenteeism, which is defined as attending work while sick. Researchers argue that the effect of bullying on sickness absence might not be as obvious as first expected because bullied individuals will have a greater tendency to attend work even though they feel sick. There are several reasons for this. Not attending work might be thought to imply a lack of commitment to the workplace. In highly stressful workplaces, where notification of illness causes grief for colleagues, targets might be afraid of creating yet another reason to be harassed. The targets will also lose control of their work when they are away. They might be excluded from important decisions, or they might be deprived of their original work tasks (Conway et al., 2016). Conway et al. (2016) also find that frequently bullied individuals more often attend work even though they are ill compared to non-bullied individuals; however, the significance of the results disappears once they condition on baseline presenteeism. ${ }^{39}$ The questionnaire asks respondents to state how many days they went to work during the past year. Again, this measure is subject to issues such as recall bias, reverse causality, and common source bias, and results should be interpreted keeping this in mind. The coefficient on presenteeism in Table 11 is equal to 1.2 days for women and 2.8 days for men. Both estimates, however, are insignificant due to large standard errors. We cannot reject that the bullied individuals have the same amount of presenteeism as non-bullied individuals, but the results point in the direction that men may have a greater tendency to attend work even though they feel sick. This is a possible explanation as to why we do not observe more sickness absence among men subject to workplace bullying.

\subsection{Turnover and employment}

As mentioned above, bullying is also likely to affect the individual's attachment to the workplace. It is possible that men are more likely to leave the workplace if they are exposed to workplace bullying, whereas women stay and try to mend things. Or it could be that men's outside options in the labor market are better compared to women's,

\footnotetext{
${ }^{39}$ Their analysis is based on the same data source as used in this paper. They define bullying by self-labeling according to the definition of bullying (see section 2).
} 
Table 11: OLS Results: Workplace Bullying and Potential Work-Related Mechanisms

\begin{tabular}{lcccc}
\hline & Presenteeism & $\begin{array}{c}\text { Employed at Same } \\
\text { Workplace 2011 (0/1) }\end{array}$ & $\begin{array}{c}\text { Employment } \\
2011(0 / 1)\end{array}$ & $\begin{array}{c}\text { Log Wage } \\
\text { Income 2011 }\end{array}$ \\
\hline $\begin{array}{l}\text { Female Sample } \\
\text { Main Conditioning Set }\end{array}$ & & & \\
Bullied (0/1) & 1.175 & -0.036 & 0.037 & 0.016 \\
Std. Error & $(0.909)$ & $(0.036)$ & $(0.037)$ & $(0.027)$ \\
Observations & 2107 & 2169 & 2169 & 1795 \\
Mean & 4.495 & 0.422 & 0.828 & 12.553 \\
Male Sample & & & & \\
Main Conditioning Set & & & & \\
Bullied (0/1) & 2.924 & -0.053 & -0.065 & -0.044 \\
Std. Error & $(3.017)$ & $(0.041)$ & $(0.046)$ & $(0.027)$ \\
Observations & 984 & 1013 & 1013 & 823 \\
Mean & 4.919 & 0.448 & 0.812 & 12.738 \\
\hline
\end{tabular}

The standard errors are clustered at the workplace level. ***: Significant at a $1 \%$ level. **: Significant at a 5\% level. *: Significant at a $10 \%$ level. The full set of estimates is available from the authors upon request.

making it easier for men to change workplace or occupation compared to women. We construct a dummy variable equal to one if the respondent is still employed in the same workplace in 2011 as at the time of the survey in 2006. The results are reported in Table 11. Both point estimates for men and women are negative, suggesting that bullied individuals are more likely to have left the workplace by 2011. However, none are significant. A further analysis shows that women are significantly more likely to leave in 2010, implying that leaving the workplace is a possible coping strategy for women. This may explain why we observe that the significant difference in long-term sickness absence disappears after 2009.

Turnover, of course, relies on the fact that an individual is in employment. If targets of bullying in general are less likely to be employed, it will affect the results above. We construct a variable employment equal to one if an individual has accumulated at least six months of work experience in a given year. According to this definition, $82 \%$ of the women and $83 \%$ of the men are in employment in 2011. Table 11 shows no significant differences in employment rates between bullied and non-bullied individuals in 2011 for either men or women. Consequently, being a target of bullying does not mean that individuals are less likely to be employed over time. ${ }^{40}$

\footnotetext{
${ }^{40}$ If we define employment to be at least nine months of work experience, we do find that men are less
} 
Leaving one's workplace if subject to bullying is of course only effective if bullying is due to workplace characteristics and not personal characteristics. In case of the latter, we would expect bullying to reoccur in a new workplace. In subsection $3.3 .1,27 \%$ of $\mathrm{AB}$ reported being bullied in a previous workplace, indicating that changing one's workplace does not eliminate the threat of being bullied. Eight percent of the PB individuals reported being bullied in their current workplace, suggesting that either the bullying stopped or they made a transition within the workplace. Thus, although bullying does not appear to affect employment, it may still affect the individual's experience profile through an increase in transitions within and between workplaces, which could be costly in terms of, for instance, loss of promotions, future benefit levels, and pensions. While we cannot observe transitions within workplaces we can investigate differences in logwage income in 2011 between the individuals who were bullied in 2006 and those who were not. We restrict this analysis to individuals in employment. Table 11 shows the results. Bullied men earn $4 \%$ less than non-bullied men, which in monetary terms translates into approximately USD1,900 a year. It is, however, insignificant with a p-value of 0.11. The point estimate indicates a wage increase of $1.6 \%$ for women who are subject to bullying, but it is highly insignificant. These results suggest that, although exposure to bullying does not appear to affect employment rates, bullying may affect the individual's experience profile in the labor market. Future research should take a deeper look at the dynamics between bullying and the transitions within and between workplaces to gain a better understanding of the potential costs of bullying briefly touched upon in this section.

\subsection{Leaving the labor force}

A final reason for why we may see that the relationship between bullying and sickness absence is lacking for men and disappears for women could be that the individuals who are exposed to bullying leave the labor force, in which case it is not possible to observe sickness absence. In order to measure whether an individual is outside the labor force, we construct a measure which is equal to one if an individual has spent more than six months outside DREAM, in which case we do not observe any public transfer, and more likely to be employed in 2011 if exposed to bullying. 
than 25 weeks of work experience are not accumulated either $($ employment $=0)$.

Table 12: OLS Results: Workplace Bullying and Out of the Labor Force

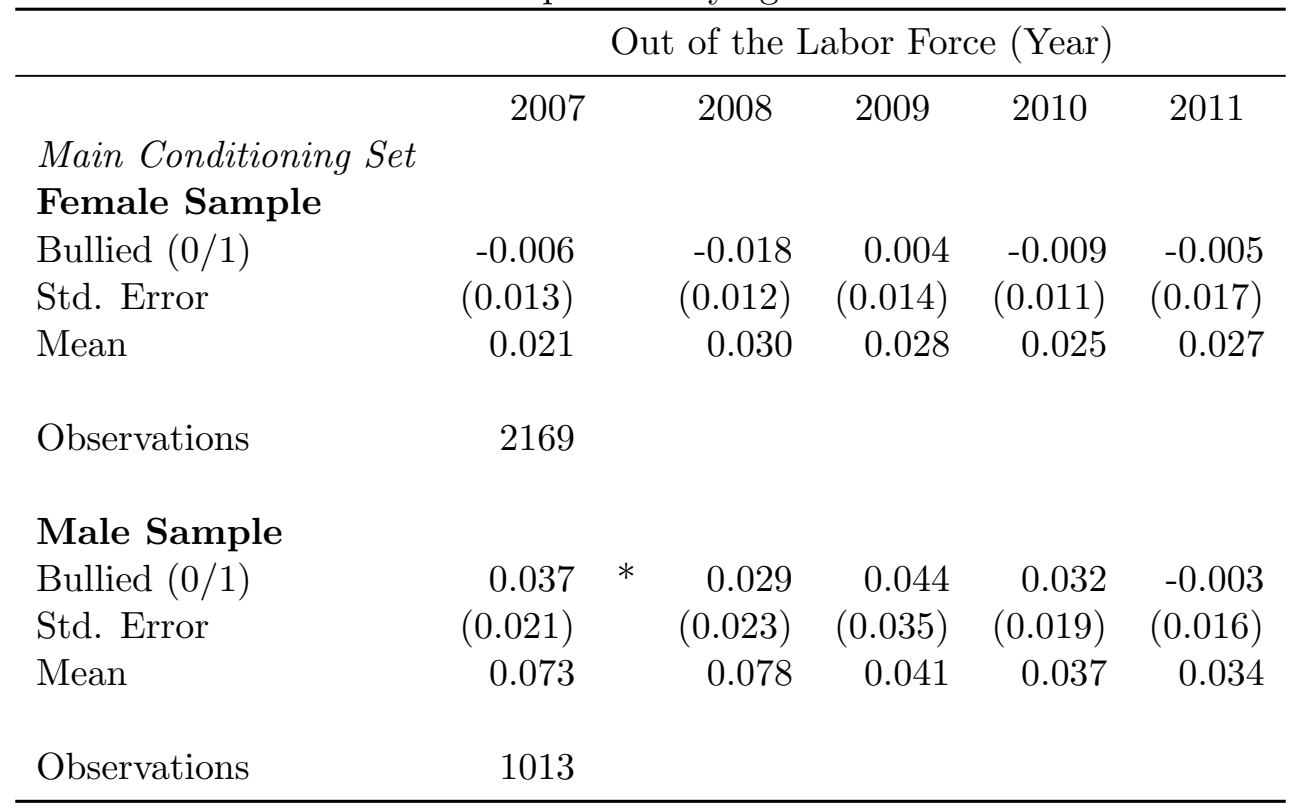

Notes: The main conditioning set includes individual and work-related characteristics and previous health. The standard errors are clustered at the workplace level. ${ }^{* *}$ : Significant at a $1 \%$ level. ${ }^{* *}$ : Significant at a $5 \%$ level. *: Significant at a $10 \%$ level. The full set of estimates is available from the authors upon request.

Table 12 reports the results. We see that women are neither statistically nor economically more or less likely to leave the labor force after exposure to bullying. ${ }^{41}$ For the male sample, the numbers indicate that $3-4 \%$ of men may in fact be more likely to leave the labor force in the two years following being bullied. This is compared to an average of $7 \%$ of non-bullied men being outside the labor force in 2006 and 2007. Thus, bullied men appear to be almost twice as likely to leave the labor force than their non-bullied colleagues, which could explain why we do not observe that bullying is associated with increases in long-term sickness absence for men. The numbers, however, are insignificant (the coefficient in 2007 is significant at a $10 \%$ level), probably due to the small sample size. Five years after being exposed to bullying, men are, just like women, no more or less likely to leave the labor force than their non-bullied colleagues.

\footnotetext{
${ }^{41}$ On average $2 \%$ of the women are observed to be outside the labor force in $2007-2011$.
} 
Although men and women seem to be exposed to the same kind of bullying behavior and both genders have significantly worse immediate health when exposed to bullying, this section indicates that bullying only has adverse long-term effects on health for women. Either the health of men is not severely affected by bullying (as seeking medical attention due to bullying is perhaps too stigmatizing), or they have a tendency to attend work while sick. Our results are consistent with this explanation, but it is difficult to draw inferences from them. The results do not appear to be due to the shirking behavior of either men or women. We also test whether the lack of results for men is due to the fact that they leave the workplace, employment, or the labor force. Our findings indicate that men leave the labor force for a short period of time, but the results are insignificant.

We do not address the perception of bullying in this paper. Although men report at least as many, if not more, and more frequent NA, they might not perceive the actions to be as negative as women do. Similarly, we cannot address who commits the NA. From the questionnaire, we know that $10 \%$ of the women and $15 \%$ of the men report that they have committed at least one of the NA themselves. It could be the case that the actions are more harmful if committed by the opposite gender, in which case we would expect women to be more affected. Another concern is that women are highly overrepresented in this sample. It would be relevant to conduct the same analysis on a representative sample of workplaces before concluding that men are not affected by bullying in terms of deteriorated health and increased sickness absence.

\section{Conclusion}

This paper investigates the detrimental effects on sickness absence of being exposed to workplace bullying in a sample of Danish workplaces. As a measure of workplace bullying, we employ the NAQ-R, which is thought to be more reliable than the selflabeling of being bullied. In addition, we obtain registry-based information on previous sickness absence as well as mental health measures, such as prescription drug use, and diagnoses of behavioral and mental disorders. Both are plausible confounders. Our results show that, although men and women are exposed to the same types of negative behavior and both have significantly worse immediate health when exposed to bullying, we only observe a significant relationship on long-term sickness absence for women. The 
estimates show that being exposed to workplace bullying doubles long-term sickness absence (by about two weeks a year) for women. In other words, a $50 \%$ reduction in the probability of being bullied causes the same decrease in sickness absence as a $5 \%$ increase in the cost of sickness absence. The results are robust to the inclusion of personality traits and workplace characteristics.

It is puzzling that the exposure to bullying does not lead to increased levels of absence for men. We test whether health and coping strategies can explain this. We find that bullying is not associated with short-term sickness absence for either gender in the sample of public employees. Insofar that we consider long-term sickness absence to reflect poor health and not shirking behavior, being exposed to workplace bullying is only associated with adverse health for women, and neither gender is more likely to shirk as a result of bullying. For women, we found increases in the use of antidepressant medication in the years after bullying, indicating long-term health consequences of exposure to bullying. For men, we found no significant effects on long-term health, although there was some indication that men reported higher levels of presenteeism when exposed to bullying. Finally, we investigated whether the absence of significant differences could be explained by turnover or lack of labor force participation. We found that women are significantly more likely to leave their workplace in 2010, possibly explaining why the relationship with long-term sickness absence disappears after 2009. Men, however, appear to receive lower wage income when exposed to bullying, which could indicate that bullying affects, e.g., their within workplace transitions and promotion probabilities. Furthermore, the findings on men may indicate that they are more likely to leave the labor force when exposed to bullying, which may explain why we did not observe more sickness absence for men after the exposure to bullying. The results, however, were insignificant, ${ }^{42}$ possibly due to a relatively small sample size of men.

We were not able to investigate whether the differences in the results for men and women were due to differences in characteristics of the perpetrators of bullying. Previous studies (Kivimaki et al., 2000, Ortega et al., 2011), unfortunately, do not consider heterogeneity in gender, which means that further investigation is needed in order to observe whether our findings are general. Finally, we want to stress that the effects of the

\footnotetext{
${ }^{42}$ The coefficient on being out of the labor force in 2007 was significant at a $10 \%$ level.
} 
exposure to workplace bullying are particularly difficult to identify, and our estimates should be interpreted with this in mind.

The results point toward significant benefits from reducing workplace bullying. From a manager's point of view, implementing strategies to reduce workplace bullying thus appears to be best practice. So why does bullying still take place in firms? First, we cannot reject that bullying is a consequence of personal characteristics. At the same time, we also find that workplace characteristics seem to matter. Only a few intervention studies on workplace bullying have been conducted, and their level of quality is not satisfactory enough to permit unambiguous recommendations (Hodgins et al., 2014). This is probably a reflection of the fact that we still lack knowledge on what causes bullying. As a result, an important next step for future research is to look into the dynamics of bullying and the transitions within and between workplaces. This will give us a better understanding of whether it is the workplace itself, the composition of the employees, or the personal characteristics of the individuals that can explain exposure to bullying. 


\section{References}

Agervold, M., Mikkelsen, E. G., 2004. Relationships between bullying, psychosocial work environment and individual stress reactions. Work and Stress 18 (4), 336 - 351.

Agnew, R., 1992. Foundation for a general strain theory of crime and delinquency*. Criminology 30 (1), 47-88.

Aquino, K., 2000. Structural and individual determinants of workplace victimization: the effects of hierarchical status and conflict management style. Journal of Management $26(2), 171-193$.

Aquino, K., Bradfield, M., 2000. Perceived victimization in the workplace: The role of situational factors and victim characteristics. Organization Science 11 (5), 525-537.

Bakker, A. B., Demerouti, E., 2007. The job demands-resources model: State of the art. Journal of managerial psychology 22 (3), 309-328.

Bratberg, E., Monstad, K., 2015. Worried sick? worker responses to a financial shock. Labour Economics 33, 111-120.

Conway, P. M., Clausen, T., Hansen, A. M., Hogh, A., 2016. Workplace bullying and sickness presenteeism: cross-sectional and prospective associations in a 2-year followup study. International Archives of Occupational and Environmental Health 89 (1), $103-114$.

Costa, P. T., McCrae, R. R., 1980. Influence of extraversion and neuroticism on subjective well-being: happy and unhappy people. Journal of personality and social psychology $38(4), 668$.

Derks, B., Ellemers, N., van Laar, C., de Groot, K., 2011. Do sexist organizational cultures create the queen bee? British Journal of Social Psychology 50 (3), 519-535.

Einarsen, S., Hoel, H., Notelaers, G., 2009. Measuring exposure to bullying and harassment at work: Validity, factor structure and psychometric properties of the negative acts questionnaire-revised. Work and Stress 23 (1), $24-44$. 
Eriksen, W., Einarsen, S., 2004. Gender minority as a risk factor of exposure to bullying at work: The case of male assistant nurses. European Journal of Work and Organizational Psychology 13 (4), 473 - 492.

for Labour Market, D. A., Recruitment, 2010. Når en medarbejder melder sig syg - nye muligheder og pligter. Arbejdsmarkedsstyrelsen.

Hansen, Å. M., Hogh, A., Persson, R., 2011. Frequency of bullying at work, physiological response, and mental health. Journal of Psychosomatic Research 70 (1), 19-27.

Hodgins, M., MacCurtain, S., Mannix-McNamara, P., 2014. Workplace bullying and incivility: a systematic review of interventions. International Journal of Workplace Health Management 7 (1), 54-72.

Hogh, A., Henriksson, M. E., Burr, H., 2005. A 5-year follow-up study of aggression at work and psychological health. International Journal of Behavioral Medicine 12 (4), $256-265$.

Ichino, A., Riphahn, R. T., 2005. The effect of employment protection on worker effort: Absenteeism during and after probation. Journal of the European Economic Association 3 (1), 120-143.

Johansson, P., Palme, M., 1996. Do economic incentives affect work absence? empirical evidence using swedish micro data. Journal of Public Economics 59 (2), 195-218.

Johansson, P., Palme, M., 2005. Moral hazard and sickness insurance. Journal of Public Economics 89 (9), 1879-1890.

Kivimaki, M., Elovainio, M., Vahtera, J., 2000. Workplace bullying and sickness absence in hospital staff. Occupational and Environmental Medicine 57 (10), 656-660.

Kivimäki, M., Virtanen, M., Vartia, M., Elovainio, M., Vahtera, J., KeltikangasJärvinen, L., 2003. Workplace bullying and the risk of cardiovascular disease and depression. Occupational and Environmental Medicine 60 (10), 779-783.

Kristofferzon, M.-L., L'ofmark, R., Carlsson, M., 2003. Myocardial infarction: gender differences in coping and social support. Journal of Advanced Nursing 44 (4), 360-374. 
Matthiesen, S. b., Einarsen, S., 2007. Perpetrators and targets of bullying at work: Role stress and individual differences. Violence and Victims 22 (6), 735 - 753.

Mikkelsen, E. G., Einarsen, S., 2001. Bullying in danish work-life: Prevalence and health correlates. European Journal of Work and Organizational Psychology 10 (4), 393 413.

Niedhammer, I., David, S., Degioanni, S., 2006. Association between workplace bullying and depressive symptoms in the french working population. Journal of Psychosomatic Research 61 (2), $251-259$.

Nielsen, M. B., Einarsen, S., 2012. Outcomes of exposure to workplace bullying: A meta-analytic review. Work \& Stress 26 (4), 309-332.

Nielsen, M. B., Matthiesen, S. B., Einarsen, S., 2010. The impact of methodological moderators on prevalence rates of workplace bullying. a meta-analysis. Journal of Occupational and Organizational Psychology 83, 955 - 979.

Nielsen, M. B., Skogstad, A., Matthiesen, S. B., Glasø, L., Aasland, M. S., Notelaers, G., Einarsen, S., 2009. Prevalence of workplace bullying in norway: Comparisons across time and estimation methods. European Journal of Work and Organizational Psychology 18 (1), 81-101.

OECD, 2010. Sickness, disability and work: Breaking the barriers. Tech. rep., OECD, iSBN 978-92-64-08885-6.

Ortega, A., Christensen, K. B., Hogh, A., Rugulies, R., Borg, V., 2011. One-year prospective study on the effect of workplace bullying on long-term sickness absence. Journal of Nursing Management 19 (6), 752-759.

Ose, S. O., 2005. Working conditions, compensation and absenteeism. Journal of health economics 24 (1), 161-188.

Pejtersen, J. H., Kristensen, T. S., Borg, V., Bjorner, J. B., 2010. The second version of the copenhagen psychosocial questionnaire. Scandinavian Journal of Public Health 38 (3 suppl), 8-24. 
Røed, K., Fevang, E., 2007. Organizational change, absenteeism, and welfare dependency. Journal of Human Resources 42 (1), 156-193.

Setterlind, S., Larsson, G., 1995. The stress profile: A psychosocial approach to measuring stress. Stress Medicine 11 (1), 85-92.

Vartia, M., 2001. Consequences of workplace bullying with respect to the well-being of its targets and the observers of bullying. Scandinavian Journal of Work, Environment and Health 27 (1), $63-69$.

Watson, D., Clark, L. A., 1984. Negative affectivity: The disposition to experience aversive emotional states. Psychological Bulletin 96 (3), 465.

Watson, D., Clark, L. A., Tellegen, A., 1988. Development and validation of brief measures of positive and negative affect: The panas scales. Journal of Personality and Social Psychology 54 (6), 1063.

Ziebarth, N. R., Karlsson, M., 2010. A natural experiment on sick pay cuts, sickness absence, and labor costs. Journal of Public Economics 94 (11), 1108-1122.

Ziebarth, N. R., Karlsson, M., 2014. The effects of expanding the generosity of the statutory sickness insurance system. Journal of Applied Econometrics 29 (2), 208230. 


\section{A Attrition}

The response rate in the questionnaires was $45.9 \%$. The Integrated Database for Labor Market Research (IDA) contains all individuals registered to be working at the workplaces of the respondents, thus allowing a comparison of characteristics of the respondents and non-respondent observed in the Danish registry data. Note that our sample here is larger than the original sample of respondents who received the questionnaires. Only workplaces are observed in IDA, but it may be particular departments of a workplace that received the questionnaire. Unfortunately, we do not have access to the civil registration numbers of the non-respondents. Our results, however, give an indication of the differences between the respondents and the population of workers at their workplaces. We run a probit regression on a binary indicator of whether the individual answered the questionnaire or not using a range of characteristics. Table A summarizes marginal effects and standard errors. We observe significant differences in many demographic characteristics; however, these differences are likely to be due to a large sample size since the coefficients are close to zero, e.g., age and tenure. In general, there is no clear pattern in the coefficients. Respondents are slightly less likely to have a higher education (bachelor degree and above); however, they are at the same time much more likely to be employed in a top management position. Full-time employees and private sector employees are much more likely to answer the questionnaire. The sum of weeks of sickness absence from 2001 to 2005 is significant at a 10\% level, but, again, the coefficient is very small. If anything, the table indicates that individuals who have a better job, are married, and of Danish origin, and thus individuals we would expect to be less likely to be bullied, who responded to the questionnaire. In so far that bullying increases sickness absence, this would downward bias our results.

Table A Probit Regression: Propensity to Answer Survey

\begin{tabular}{lcrr}
\hline & \multicolumn{3}{c}{ Answered Survey $(0 / 1)$} \\
& Mean & Std. Error \\
\hline Male $(0 / 1)$ & -0.041 & $* * *$ & $(0.005)$ \\
Age & 0.003 & $* * *$ & $(0.000)$ \\
Divorce $(0 / 1)$ & 0.014 & & $(0.014)$ \\
\hline Continued on next page & & \\
\hline Notes: ${ }^{* * *}:$ Significant at a 1\% level. ${ }^{* *}:$ Significant at a 5\% level. *: Signi- \\
ficant at a 10\% level. All variables are measured in 2005 unless stated otherwise.
\end{tabular}


Table A Continued -

\begin{tabular}{|c|c|c|c|}
\hline \multirow[b]{3}{*}{ Years since Divorce } & \multicolumn{3}{|c|}{ Answered Survey $(0 / 1)$} \\
\hline & \multicolumn{2}{|c|}{ Mean } & \multirow{2}{*}{$\frac{\text { Std. Error }}{(0.001)}$} \\
\hline & -0.002 & $* *$ & \\
\hline Cohabiting (omit var. $=$ Single $)$ & 0.001 & & $(0.008)$ \\
\hline Married (omit var. $=$ Single) & 0.017 & $* *$ & $(0.008)$ \\
\hline Ethnic $(0 / 1)$ & -0.049 & $* * *$ & $(0.009)$ \\
\hline Higher Educational Level $(0 / 1)$ & -0.005 & & $(0.008)$ \\
\hline Children $0-2$ years $(0 / 1)$ & -0.018 & $* *$ & $(0.008)$ \\
\hline Children $3-5$ years $(0 / 1)$ & 0.008 & & $(0.008)$ \\
\hline Children $6-10$ years $(0 / 1)$ & -0.002 & & $(0.007)$ \\
\hline Children $11-18$ years $(0 / 1)$ & 0.017 & $* * *$ & $(0.006)$ \\
\hline \multicolumn{4}{|l|}{ Work-related Characteristics (W) } \\
\hline Tenure & 0.000 & & $(0.000)$ \\
\hline Full-time Employee (omit. var $=$ Part-time) & 0.081 & $* * *$ & $(0.008)$ \\
\hline Private Sector (omit. var $=$ Public) & 0.203 & $* * *$ & $(0.011)$ \\
\hline \multicolumn{4}{|c|}{ Employment (omit. var $=$ Lower Level Employee) } \\
\hline Top Management Level & 0.081 & $* * *$ & $(0.027)$ \\
\hline Higher Management Level & 0.088 & $* * *$ & $(0.012)$ \\
\hline Medium Level Employee & 0.019 & $* *$ & $(0.009)$ \\
\hline Other Employment & -0.005 & & $(0.008)$ \\
\hline Selfemployment & -0.085 & $* *$ & $(0.038)$ \\
\hline Unemployment & -0.013 & & $(0.022)$ \\
\hline Average Earnings 2001-2005 & 0.003 & $*$ & $(0.002)$ \\
\hline Weeks of Unemployment 2001-2005 & -0.000 & $* * *$ & $(0.000)$ \\
\hline \multicolumn{4}{|l|}{ Previous Health $(\boldsymbol{H})$} \\
\hline Weeks of Sickness Ábsence 2001-2005 & -0.000 & $*$ & $(0.000)$ \\
\hline Antidepressants 2001-2005 (0/1) & -0.003 & & $(0.009)$ \\
\hline Psycholeptics 2001-2005 (0/1) & -0.015 & $* *$ & $(0.007)$ \\
\hline Mental or Behavioral Diagnosis $(0 / 1)$ & 0.004 & & $(0.012)$ \\
\hline Workplace Fixed Effects & Yes & & \\
\hline Observations & 20,543 & & \\
\hline Pseudo $\mathrm{R}^{2}$ & 0.064 & & \\
\hline
\end{tabular}

ficant at a $10 \%$ level. All variables are measured in 2005 unless stated otherwise. 


\section{B Firm Representativeness}

This section compares the level of sickness absence in participating firms to the level of sickness absence in non-participating firms by industry. In general, the levels are significantly different, but the participating firms do not appear to systematically have a higher level of sickness absence compared to non-participating firms.

Table B Representativeness in Sickness Absence of Participating Firms by Industry.

\begin{tabular}{|c|c|c|c|c|c|c|c|}
\hline Industry & $\begin{array}{c}\text { Population } \\
\text { Sick. Abs. } \\
2005\end{array}$ & $\begin{array}{c}\text { Population } \\
\text { Obs. }\end{array}$ & $\begin{array}{l}\text { Sample } \\
\text { Sick. Abs. } \\
2005\end{array}$ & $\begin{array}{l}\text { Std. } \\
\text { Dev. }\end{array}$ & $\begin{array}{c}\text { Sample } \\
\text { Obs. }\end{array}$ & $\begin{array}{l}\text { Z-test } \\
\text { Statistic }\end{array}$ & P-Value \\
\hline Canned fish, minced fish, and fish filet factories & 0.948 & 3509 & 0.488 & 1.664 & 86 & 23.740 & 0.000 \\
\hline Production of fruit and vegetable juice & 0.805 & 226 & 0.989 & 4.790 & 183 & -7.020 & 0.000 \\
\hline Bread factories & 0.639 & 3118 & 0.653 & 3.222 & 144 & -0.607 & 0.544 \\
\hline $\begin{array}{l}\text { Publication of books, brochures, etc. without } \\
\text { own printery }\end{array}$ & & 2873 & 2500 & 8.210 & 22 & -5.314 & \\
\hline Concrete panel factories & $\begin{array}{l}0.517 \\
0.831\end{array}$ & $\begin{array}{l}2873 \\
4021\end{array}$ & 0.653 & $\begin{array}{l}8.210 \\
3.303\end{array}$ & $\begin{array}{l}22 \\
98\end{array}$ & $\begin{array}{c}-5.314 \\
5.291\end{array}$ & $\begin{array}{l}0.000 \\
0.000\end{array}$ \\
\hline Asphalt and roofing cardboard factories & 0.681 & 1438 & 0.534 & 2.492 & 266 & 15.686 & 0.000 \\
\hline Production of other finished metal products & 0.723 & 8108 & 0.859 & 4.442 & 311 & -9.516 & 0.000 \\
\hline Production of packaging machines & 0.623 & 983 & 0.724 & 4.527 & 98 & -2.206 & 0.027 \\
\hline Production of parts and accessories for motor & & & & & & & \\
\hline vehicles & 0.797 & 3855 & 0.376 & 3.076 & 468 & 63.992 & 0.000 \\
\hline Recycling of metal scrap products & 0.652 & 394 & 0.341 & 2.063 & 132 & 19.921 & 0.000 \\
\hline Building and civil engineering contractors & & & & & & & \\
\hline (not demolition and earthmoving contractors) & 0.738 & 48,023 & 1.875 & 6.796 & 168 & -28.113 & 0.000 \\
\hline Wholesale trade with waste products & 1.050 & 1992 & 0.623 & 4.124 & 53 & 5.495 & 0.000 \\
\hline Department stores & 0.330 & 27,616 & 0.308 & 1.532 & 78 & 1.145 & 0.254 \\
\hline Railways & 0.709 & 8247 & 0.486 & 2.138 & 251 & 26.144 & 0.000 \\
\hline Chartered flights with cargo & 0.468 & 1103 & 0.758 & 3.627 & 363 & -28.998 & 0.000 \\
\hline Central banks & 0.826 & 24,657 & 1.254 & 5.488 & 642 & -50.060 & 0.000 \\
\hline Non-profit housing associations & 0.795 & 10,041 & 0.514 & 1.967 & 37 & 5.304 & 0.000 \\
\hline Research and development in natural science & 0.349 & 11,692 & 0.523 & 3.445 & 1,203 & -60.691 & 0.000 \\
\hline $\begin{array}{l}\text { Public administration in health care, teaching, } \\
\text { and social conditions }\end{array}$ & 0.690 & 15,377 & 11.000 & 22.956 & , & -2.246 & 0025 \\
\hline Public administration in industry, infrastucture, etc. & 0.631 & 12,649 & 0.852 & 3.619 & 189 & -11.529 & 0.000 \\
\hline Courts & 0.684 & 3150 & 0.273 & 1.515 & 44 & 11.946 & 0.000 \\
\hline Social insurance & 0.738 & 2462 & 0.198 & 0.833 & 91 & 59.020 & 0.000 \\
\hline Public schools etc & 0.703 & 90,915 & 0.677 & 3.702 & 220 & 1.542 & 0.000 \\
\hline Schools with commercial and clerical education & & & & & & & \\
\hline and training & 0.577 & 6747 & 0.836 & 5.690 & 67 & -3.053 & 0.002 \\
\hline Schools with industrial and technical training & 0.744 & 9825 & 1.287 & 6.679 & 178 & -14.466 & 0.000 \\
\hline Schools with health and welfare care educations & 0.868 & 6316 & 0.954 & 5.918 & 152 & -2.209 & 0.028 \\
\hline Universities & 0.433 & 20,564 & 0.300 & 2.643 & 1,542 & 78.112 & 0.000 \\
\hline Teacher training colleges & 0.555 & 2778 & 0.000 & 0.000 & 43 & - & - \\
\hline Colleges with humanistic and artistic educations & 0.394 & 1244 & 0.000 & 0.000 & 60 & - & - \\
\hline Colleges with health educations & 0.671 & 523 & 0.395 & 2.457 & 177 & 19.859 & 0.000 \\
\hline Colleges with vocational adult education & 0.714 & 3142 & 1.698 & 7.606 & 106 & -13.721 & 0.000 \\
\hline Adult education colleges & 0.993 & 2119 & 0.444 & 2.711 & 99 & 20.044 & 0.000 \\
\hline Hospitals & 0.766 & 107,489 & 0.785 & 4.134 & 10,852 & -52.080 & 0.000 \\
\hline Practising dentists & 0.623 & 13,587 & 1.057 & 4.701 & 87 & -8.037 & 0.000 \\
\hline Old people's homes and sheltered housing & 1.131 & 97,709 & 0.940 & 4.558 & 1,041 & 43.548 & 0.000 \\
\hline Care homes etc & 1.110 & 2651 & 0.000 & 0.000 & 43 & - & - \\
\hline Nurseries & 0.913 & 8437 & 0.370 & 1.363 & 27 & 10.750 & 0.000 \\
\hline Kindergartens & 1.029 & 25,957 & 1.643 & 7.519 & 42 & -3.429 & 0.001 \\
\hline After School Clubs etc. & 0.991 & 21,174 & 2.625 & 6.826 & 24 & -5.744 & 0.000 \\
\hline Day Care Centers (age 0-6) & 1.029 & 35,361 & 2.577 & 8.194 & 26 & -4.911 & 0.000 \\
\hline Home care & 1.234 & 10,014 & 0.947 & 3.093 & 264 & 24.484 & 0.000 \\
\hline Collection of waste & 0.933 & 3568 & 0.000 & 0.000 & 4 & - & - \\
\hline Refuse collection, snow clearing, etc. & 0.934 & 7626 & 2.228 & 8.373 & 79 & -12.205 & 0.000 \\
\hline Employers' and industrial organizations & 0.366 & 6097 & 0.000 & 0.000 & 16 & - & - \\
\hline Professional Informative Associations & 0.429 & 1669 & 0.866 & 5.387 & 112 & -9.087 & 0.000 \\
\hline Unions & 0.773 & 11,056 & 0.176 & 0.929 & 199 & 127.820 & 0.000 \\
\hline Public libraries & 0.571 & 6990 & 1.167 & 4.168 & 84 & -12.004 & 0.000 \\
\hline Sports clubs & 0.598 & 6814 & 0.059 & 0.382 & 68 & 95.993 & 0.000 \\
\hline
\end{tabular}

\section{The Negative Acts Questionnaire-Revised}


Table C Frequency of Negative Actions for Those Exposed to Bullying.

\begin{tabular}{|c|c|c|c|c|c|c|c|}
\hline & & \multicolumn{5}{|c|}{ Frequency $(\%)$} & \multirow[b]{2}{*}{ Obs. } \\
\hline & & Never & $\begin{array}{l}\text { Now and } \\
\text { Then }\end{array}$ & Monthly & Weekly & Daily & \\
\hline \multicolumn{8}{|c|}{ Work-related Bullying } \\
\hline Q1 & $\begin{array}{l}\text { Someone withholding information which affects } \\
\text { your performance }\end{array}$ & 13.2 & 43.2 & 10.6 & 22.5 & 10.6 & 227 \\
\hline Q3 & $\begin{array}{l}\text { Being ordered to do work below your level of } \\
\text { competence }\end{array}$ & 21.7 & 27.0 & 8.0 & 25.2 & 18.1 & 226 \\
\hline Q14 & Having your opinions ignored & 12.8 & 52.9 & 9.7 & 18.9 & 5.7 & 227 \\
\hline Q16 & Being given tasks with unreasonable deadlines & 19.7 & 32.9 & 11.8 & 23.3 & 12.3 & 228 \\
\hline Q18 & Excessive monitoring of your work & 49.6 & 26.3 & 6.1 & 7.5 & 10.5 & 228 \\
\hline Q19 & $\begin{array}{l}\text { Pressure not to claim something to which } \\
\text { by right you are entitled (e.g. sick leave, } \\
\text { holiday entitlement, travel expenses) }\end{array}$ & 56.4 & 32.4 & 6.7 & 2.7 & 1.8 & 225 \\
\hline Q21 & Being exposed to an unmanageable workload & 23.9 & 26.6 & 8.9 & 24.3 & 16.4 & 226 \\
\hline \multicolumn{8}{|c|}{ Person-related Bullying } \\
\hline Q2 & $\begin{array}{l}\text { Being humiliated or ridiculed in connection } \\
\text { with your work }\end{array}$ & 41.4 & 40.1 & 5.3 & 10.6 & 2.6 & 227 \\
\hline Q4 & $\begin{array}{l}\text { Having key areas of responsibility removed } \\
\text { or replaced with more trivial or unpleasant } \\
\text { tasks }\end{array}$ & 43.8 & 34.1 & 6.6 & 9.3 & 6.3 & 226 \\
\hline Q5 & Spreading of gossip and rumors about you & 45.2 & 32.0 & 8.3 & 8.3 & 6.1 & 228 \\
\hline Q6 & Being ignored or excluded & 53.7 & 26.4 & 6.6 & 7.5 & 5.7 & 227 \\
\hline Q7 & $\begin{array}{l}\text { Having insulting or offensive remarks made } \\
\text { about your person, attitudes or your private } \\
\text { life }\end{array}$ & 54.4 & 24.6 & 9.7 & 7.9 & 3.5 & 228 \\
\hline Q10 & $\begin{array}{l}\text { Hints or signals from others that you should } \\
\text { quit your job }\end{array}$ & 78.0 & 15.9 & 3.5 & 2.6 & 0.0 & 227 \\
\hline Q11 & Repeated reminders of your errors or mistakes & 54.2 & 31.3 & 5.7 & 7.1 & 1.8 & 227 \\
\hline Q12 & $\begin{array}{l}\text { Being ignored or facing a hostile reaction } \\
\text { when you approach }\end{array}$ & 42.3 & 38.3 & 7.9 & 7.9 & 3.5 & 227 \\
\hline Q13 & Persistent criticism of your errors or mistakes & 58.8 & 25.0 & 5.3 & 9.2 & 1.8 & 228 \\
\hline Q15 & $\begin{array}{l}\text { Practical jokes carried out by people you } \\
\text { do not get along with }\end{array}$ & 58.6 & 27.3 & 4.9 & 7.1 & 2.2 & 227 \\
\hline Q17 & Having allegations made against you & 52.2 & 37.2 & 7.1 & 1.8 & 1.8 & 226 \\
\hline Q20 & $\begin{array}{l}\text { Being the subject of excessive teasing } \\
\text { and sarcasm }\end{array}$ & 67.4 & 21.6 & 4.0 & 3.5 & 3.5 & 227 \\
\hline \multicolumn{8}{|c|}{ Physically Intimidating Bullying } \\
\hline Q8 & $\begin{array}{l}\text { Being shouted at or being the target of } \\
\text { spontaneous anger }\end{array}$ & 50.0 & 31.4 & 9.3 & 8.0 & 1.3 & 226 \\
\hline Q9 & $\begin{array}{l}\text { Intimidating behaviors such as finger-pointing, } \\
\text { invasion of personal space, shoving, blocking } \\
\text { your way }\end{array}$ & 76.3 & 11.0 & 7.9 & 3.1 & 1.8 & 228 \\
\hline
\end{tabular}




\section{Differences in Sickness Absence}

Table D Differences in Sickness Absence by Extended Bullying Categories

\begin{tabular}{|c|c|c|c|c|c|c|c|c|c|}
\hline \multirow[b]{2}{*}{ Year } & \multicolumn{3}{|c|}{ Previously Bullied } & \multicolumn{3}{|c|}{ Newly Bullied } & \multicolumn{3}{|c|}{ Always Bullied } \\
\hline & & Difference & Std. Err. & Differe & nce & Std. Err. & Differ & nce & Std. Err. \\
\hline 2000 & 0.15 & & 0.10 & -0.20 & & 0.19 & 0.15 & & 0.22 \\
\hline 2001 & 0.11 & & 0.12 & 0.02 & & 0.27 & 0.23 & & 0.29 \\
\hline 2002 & 0.34 & $* *$ & 0.12 & -0.03 & & 0.24 & 0.41 & & 0.28 \\
\hline 2003 & 0.13 & & 0.16 & -0.48 & & 0.38 & 0.43 & & 0.43 \\
\hline 2004 & 0.14 & & 0.15 & -0.20 & & 0.34 & 0.43 & & 0.38 \\
\hline 2005 & 0.07 & & 0.15 & -0.27 & & 0.38 & -0.01 & & 0.41 \\
\hline 2006 & 0.05 & & 0.15 & 0.60 & & 0.38 & 0.85 & $* *$ & 0.40 \\
\hline 2007 & 0.35 & & 0.21 & 1.69 & $* * *$ & 0.57 & 1.62 & $* * *$ & 0.59 \\
\hline 2008 & 0.22 & & 0.20 & 0.99 & $* *$ & 0.50 & 2.24 & $* * *$ & 0.56 \\
\hline 2009 & 0.44 & $*$ & 0.22 & -0.15 & & 0.49 & 3.71 & $* * *$ & 0.60 \\
\hline 2010 & 0.71 & $* * *$ & 0.21 & 0.36 & & 0.46 & 1.59 & $* * *$ & 0.53 \\
\hline 2011 & 0.36 & * & 0.19 & 0.86 & & 0.47 & 0.33 & & 0.47 \\
\hline \multirow{2}{*}{\multicolumn{2}{|c|}{$\begin{array}{l}\text { Observations } \\
\text { Observations }\end{array}$}} & s Bullied & 1162 & & & 109 & & & 95 \\
\hline & & s Never Bullied & 1561 & & & & & & \\
\hline
\end{tabular}

Notes: The coefficients in the difference columns represent the difference in long-term sickness absence relative to the never bullied individuals. ***: Significant at a $1 \%$ level. ${ }^{* *}$ : Significant at a $5 \%$ level. *: Significant at a $10 \%$ level. 


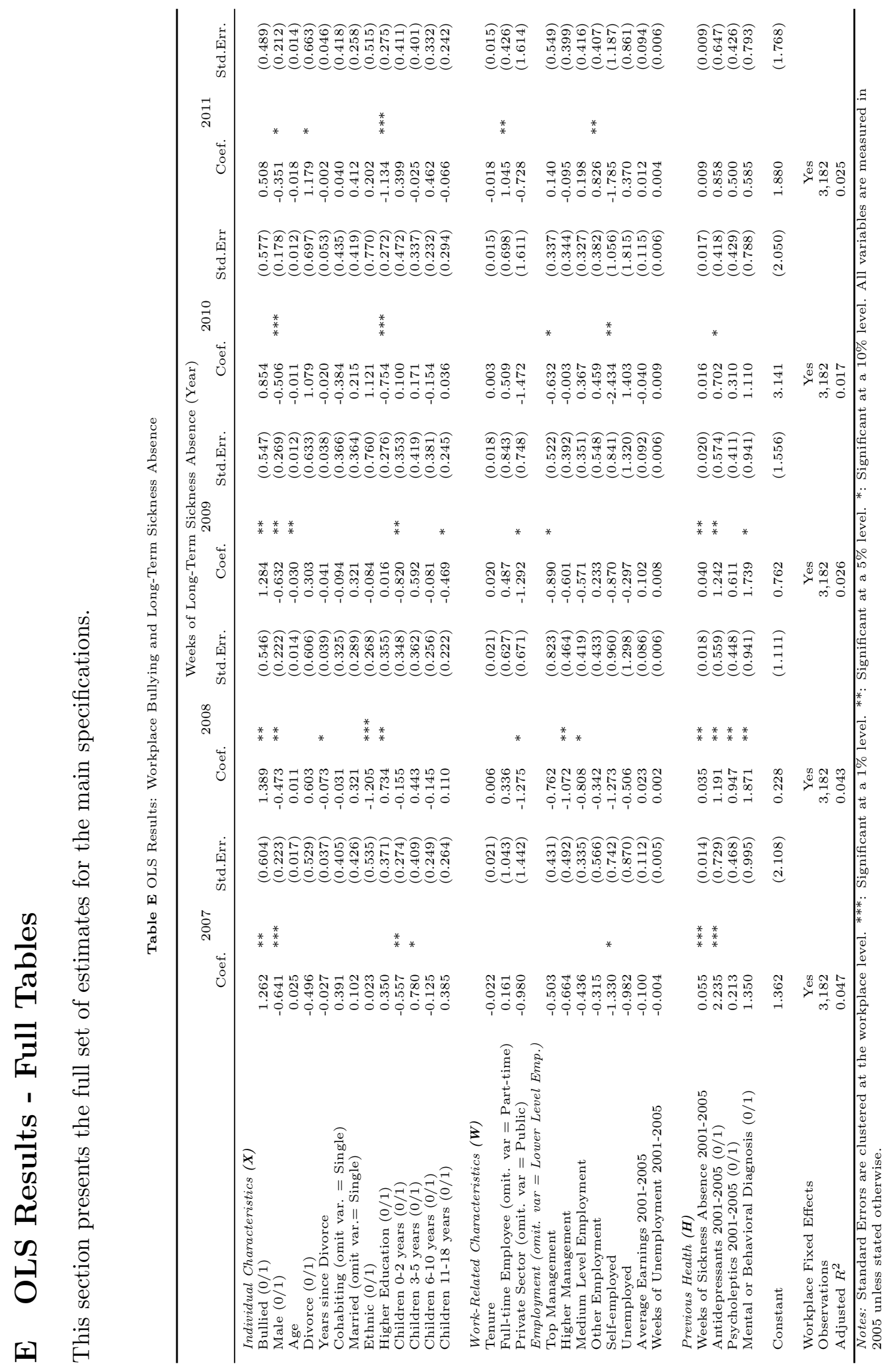




\section{F Factor Specifications}

This section specifies the factors used in the two robustness sections on personality and work environment characteristics. The factors are all extracted using confirmatory principal component analysis, and factor scores are obtained using the regression method. The table presents loadings and Cronbach's alphas.

Table F Scales: Loadings and Cronbach's alphas

\begin{tabular}{|c|c|c|c|}
\hline Category/Scale & Loadings & $\begin{array}{l}\text { Cronbach's } \\
\text { alpha }\end{array}$ & Source \\
\hline $\begin{array}{l}\text { Personality } \\
\text { Positive Affectivity } \\
\text { Attentive } \\
\text { Strong } \\
\text { Inspired } \\
\text { Active } \\
\text { Excited } \\
\text { Proud } \\
\text { Enthusiastic } \\
\text { Determined } \\
\text { Interested }\end{array}$ & $\begin{array}{l}0.632 \\
0.698 \\
0.731 \\
0.725 \\
0.577 \\
0.685 \\
0.763 \\
0.756 \\
0.787\end{array}$ & 0.872 & PANAS \\
\hline $\begin{array}{l}\text { Negative Affectivity } \\
\text { Jittery } \\
\text { Scared } \\
\text { Afraid } \\
\text { Upset } \\
\text { Irritable } \\
\text { Guilty } \\
\text { Nervous } \\
\text { Hostile } \\
\text { Distressed } \\
\text { Ashamed }\end{array}$ & $\begin{array}{l}0.734 \\
0.776 \\
0.727 \\
0.714 \\
0.652 \\
0.615 \\
0.756 \\
0.633 \\
0.751 \\
0.588\end{array}$ & 0.881 & PANAS \\
\hline $\begin{array}{l}\text { Sense of Coherence } \\
\text { I believe I can cope with most situations in life } \\
\text { I feel that what I do in my daily life is meaningful } \\
\text { I feel that I have a great deal to live for } \\
\text { I feel I understand most of what is going on in my everyday life } \\
\text { So far, I have not had any clear direction or purpose in life } \\
\text { I do not feel that I am able to influence my future to any great } \\
\text { extent } \\
\text { Often things happen around me that I do not understand } \\
\text { I know what I ought to do in my life, but I do not believe that } \\
\text { I am able to do it } \\
\text { It is difficult for me to see how different pieces in my life are } \\
\text { connected }\end{array}$ & $\begin{array}{c}-0.508 \\
-0.536 \\
0.615 \\
-0.669 \\
0.588 \\
0.587 \\
0.565 \\
0.682 \\
0.727\end{array}$ & 0.782 & $\begin{array}{l}\text { Setterlind/ } \\
\text { COPSOQ I }\end{array}$ \\
\hline
\end{tabular}


Table F Continued -

\begin{tabular}{|c|c|c|c|}
\hline Category/Scale & Loadings & $\begin{array}{l}\text { Cronbach's } \\
\text { Alpha }\end{array}$ & Source \\
\hline \multicolumn{4}{|l|}{ Demands } \\
\hline Quantitative Demands & & 0.809 & COPSOQ II \\
\hline Is your workload unevenly distributed so it piles up? & 0.732 & & \\
\hline How often do you not have time to complete all your work tasks? & 0.833 & & \\
\hline Do you get behind with your work? & 0.887 & & \\
\hline Do you have enough time for your work tasks? & -0.735 & & \\
\hline Cognitive Demands & & 0.746 & COPSOQ II \\
\hline Do you have to keep your eyes on lots of things while you work? & 0.784 & & \\
\hline Does your work require that you remember a lot of things? & 0.736 & & \\
\hline $\begin{array}{l}\text { Does your work demand that you are good at coming up with } \\
\text { new ideas? }\end{array}$ & 0.728 & & \\
\hline Does your work require you to make difficult decisions? & 0.772 & & \\
\hline Emotional Demands & & 0.832 & COPSOQ II \\
\hline Does your work put you in emotionally disturbing situations? & 0.835 & & \\
\hline Is your work emotionally demanding? & 0.887 & & \\
\hline Do you get emotionally involved in your work? & 0.842 & & \\
\hline $\begin{array}{l}\text { Do you have to relate to other people's personal problems as part } \\
\text { of your work? }\end{array}$ & 0.734 & & \\
\hline \multicolumn{4}{|l|}{ Work organization } \\
\hline Influence at work & & 0.784 & COPSOQ II \\
\hline Do you have a large degree of influence concerning your work? & 0.807 & & \\
\hline Do you have a say in choosing who you work with? & 0.754 & & \\
\hline Can you influence the amount of work assigned to you? & 0.709 & & \\
\hline Do you have any influence on what you do at work? & 0.848 & & \\
\hline Skill Discretion & & 0.794 & COPSOQ II \\
\hline Does your work require you to take the initiative? & 0.660 & & \\
\hline Do you have the possibility of learning new things & 0855 & & \\
\hline Can you use your skills or expertise in your work? & $\begin{array}{l}0.855 \\
0.732\end{array}$ & & \\
\hline $\begin{array}{l}\text { Does your work give you the opportunity to develop your } \\
\text { skills? }\end{array}$ & 0.883 & & \\
\hline \multicolumn{4}{|l|}{ Job Content } \\
\hline Meaning of Work & & 0.658 & COPSOQ II \\
\hline Is your work meaningful? & 0.864 & & \\
\hline Do you feel that the work you do is important? & 0.864 & & \\
\hline Commitment to the Workplace & & 0.752 & COPSOQ II \\
\hline Do you enjoy telling others about your place of work? & 0.808 & & \\
\hline $\begin{array}{l}\text { Do you feel that your place of work is of great importance } \\
\text { to you? }\end{array}$ & 0.697 & & \\
\hline $\begin{array}{l}\text { Would you recommend a good friend to apply for a position } \\
\text { at your workplace? }\end{array}$ & 0.806 & & \\
\hline
\end{tabular}


Table F Continued -

\begin{tabular}{lcc}
\hline Category/Scale & $\begin{array}{c}\text { Loadings } \\
\text { Cronbach's } \\
\text { Alpha }\end{array}$ & Source \\
\hline
\end{tabular}

How often do you consider looking for work elsewhere?

$-0.720$

\section{Interpersonal Relations and Management}

Predictability

COPSOQ II

At your place of work, are you informed well in advance concerning for example important decisions, changes, or plans for the future?

Do you receive all the information you need in order to do your work well?

\section{Recognition}

COPSOQ II

Is your work recognised and appreciated by the management?

Does the management at your workplace respect you?

Are you treated fairly at your workplace?

0.809

Role Clarity

Does your work have clear objectives?

Do you know exactly which areas are your responsibility?

0.842

Do you know exactly what is expected of you at work?

0.855

Role Conflicts

Do you sometimes have to do things, which ought to have been done in a different way?

Do you sometimes have to do things, which seem to be unnecessary?

COPSOQ II

To what extent would you say that your immediate superior makes sure that the individual member of staff has good development opportunities?

... gives high priority to job satisfaction?

$\ldots$ is good at work planning?

$\ldots$ is good at solving conflicts?

Social Support from Colleagues

Söderfeldt

Do you get sufficient support from your colleagues when you have too much to do?

Do you get sufficient support from you colleagues when you have to solve difficult problems?

Do you get sufficient encouragement and appraisal from your colleagues in how you do your job?

\section{Social Support from Manager}

Do you get sufficient support from your nearest manager, when you have too much to do?

Do you get sufficient support from your nearest manager,

Continued on next page - 
Table F Continued -

\begin{tabular}{|c|c|c|c|}
\hline Category/Scale & Loadings & $\begin{array}{l}\text { Cronbach's } \\
\text { Alpha }\end{array}$ & Source \\
\hline when you have to solve difficult problems? & 0.883 & & \\
\hline $\begin{array}{l}\text { Do you get sufficient encouragement and appraisal from } \\
\text { your nearest manager, in how you do your job? }\end{array}$ & 0.854 & & \\
\hline $\begin{array}{l}\text { Social Community at Work } \\
\text { Is there a good atmosphere between you and your } \\
\text { colleagues? } \\
\text { Is there good co-operation between the colleagues at work? } \\
\text { Do you feel part of a community at your place of work? }\end{array}$ & $\begin{array}{l}0.858 \\
0.874 \\
0.838\end{array}$ & 0.809 & COPSOQ II \\
\hline Insecurity & & & \\
\hline Job insecurity & & 0.799 & COPSOQ II \\
\hline Are you worried about becoming unemployed? & 0.865 & & \\
\hline Are you worried about being redundant? & 0.844 & & \\
\hline $\begin{array}{l}\text { Are you worried about being transferred to another job against } \\
\text { your will? }\end{array}$ & 0.766 & & \\
\hline $\begin{array}{l}\text { Are you worried about it being difficult for you to find another } \\
\text { job if you became unemployed? }\end{array}$ & 0.717 & & \\
\hline Values at the Workplace & & & \\
\hline Mutual Trust Between Employees & & 0.806 & COPSOQ II* \\
\hline Do the employees withhold information from each other? & 0.917 & & \\
\hline $\begin{array}{l}\text { Do the employees withhold information from the } \\
\text { management? }\end{array}$ & 0.917 & & \\
\hline Trust Regarding Management & & 0.878 & COPSOQ II* \\
\hline $\begin{array}{l}\text { Does the management trust the employees to do their } \\
\text { work well? }\end{array}$ & 0.746 & & \\
\hline $\begin{array}{l}\text { Can you trust the information that comes from the } \\
\text { management? }\end{array}$ & 0.822 & & \\
\hline $\begin{array}{l}\text { Are the employees able to express their views and } \\
\text { feelings? }\end{array}$ & 0.788 & & \\
\hline Are conflicts resolved in a fair way? & 0.817 & & \\
\hline $\begin{array}{l}\text { Are employees appreciated when they have done } \\
\text { a good job? }\end{array}$ & 0.751 & & \\
\hline $\begin{array}{l}\text { Are all suggestions from employees treated seriously } \\
\text { by the management? }\end{array}$ & 0.827 & & \\
\hline
\end{tabular}

*These two scales are constructed from the three scales, horizontal and vertical trust, and justice and respect. The three scales do not discriminate well against one another. As a result, an explorative principal component analysis was conducted and items that were cross loading were deleted. Two factors were extracted with loadings above 0.68 and named as shown. 